\title{
Marine macroinvertebrate species-area relationships, assemblage structure and their environmental drivers on submarine banks
}

\author{
C. H. Stortini ${ }^{1, *}$, B. Petrie ${ }^{2}$, K. T. Frank ${ }^{1,2}$, W. C. Leggett ${ }^{2}$ \\ ${ }^{1}$ Department of Biology, Queen's University, Kingston ON K7L 3N6, Canada \\ ${ }^{2}$ Fisheries and Oceans Canada, Bedford Institute of Oceanography, Dartmouth NS B2Y 4A2, Canada
}

\begin{abstract}
Modern extensions of the theory of island biogeography (TIB) posit that the slope of the species-area relationship (SAR) reflects the insularity of ecological communities and is strongly influenced by species' motility. We explore the relative insularity of crustacean, echinoderm and mollusk/Cirripedia assemblages in terms of both alpha diversity (species richness) and assemblage structure (relative biomass of species). These taxa/groups differ in adult motility and larval dispersal capacity. The habitats of interest were 10 offshore banks on the Scotian Shelf, Northwest Atlantic Ocean, a region dominated by the NE- to SW-flowing Nova Scotia Current (NSC). Banks in the NE tended to be larger, more heterogeneous, cooler, less saline, more retentive and more productive (higher chlorophyll a) than those in the SW. Only mollusks/Cirripedia, the least motile and dispersive group, had a significant SAR slope, supporting TIB. For crustaceans and echinoderms, temperature/salinity properties and habitat heterogeneity, respectively, were important predictors of alpha diversity. Inter-bank variation in crustacean assemblage structure was accounted for largely by bank location relative to the $\mathrm{NSC}_{i}$ the leading variables accounting for echinoderm and mollusk/Cirripedia assemblage structure were retention time and mean annual chlorophyll concentration, respectively. Along the NE to SW axis of the NSC, there was a substantial loss of species ( 7 crustacean, 9 echinoderm and 13 mollusk/Cirripedia species) and decreases in the biomass of common cold-water species. A complex interplay of species motility/ dispersal capacity, local oceanography and habitat properties determine the extent to which (1) TIB applies to submarine macroinvertebrate assemblages and (2) upstream and downstream assemblages are interconnected.
\end{abstract}

KEY WORDS: Species-area relationships · Larval transport · Macroinvertebrates · Island biogeography $\cdot$ Marine $\cdot$ Species traits $\cdot$ Biogeography $\cdot$ Motility $\cdot$ Dispersal capacity

\section{INTRODUCTION}

MacArthur \& Wilson's (1967) theory of island biogeography (TIB) posited that habitat area and species richness should be positively related due to the negative relationship between area and extinction rate. Larger areas provide a greater variety of habitats and enhanced resources, leading to larger populations of more species with a reduced risk of local extinction. Empirical tests of this theory have been

${ }^{*}$ Corresponding author: christine.stortini@gmail.com conducted across a broad range of ecosystems, including oceanic islands, ponds, streams, forest fragments, mesocosms and, most recently, submarine habitats (e.g. Frank \& Shackell 2001, Hachich et al. 2015, Stortini et al. 2018). Collectively, these studies provided support for the TIB. Large variations in the slope of the species-area relationship (SAR) have been found across ecosystem types and taxa/species groups (Drakare et al. 2006), stemming from species traits, particularly those affecting mobility (De Bie et

(C) C. H. Stortini and Fisheries and Oceans Canada 2020. Open Access under Creative Commons by Attribution Licence. Use, distribution and reproduction are unrestricted. Authors and original publication must be credited.

Publisher: Inter-Research · www.int-res.com 
al. 2012, Franzén et al. 2012, Hachich et al. 2015, van Noordwijk et al. 2015). Investigations of the role of mobility in structuring insular communities have focused principally on adult motility; little attention has been paid to the role of passive larval dispersal (but see De Bie et al. 2012). Many marine animals can be passively transported by ocean currents during early life stages (Frank 1992). With limited adult motility, passive larval transport is a particularly important process for sustaining marine macroinvertebrate populations.

In a meta-analysis of 794 SARs, Drakare et al. (2006) found that SAR slopes varied significantly among groups, habitat types, locations (mid- to high latitude, $\left.45.5^{\circ} \mathrm{S}-81.7^{\circ} \mathrm{N}\right)$, spatial scales $\left(0.01-10000 \mathrm{~m}^{2}\right)$ and with sampling schemes. While they found that SAR slopes decrease in species with greater adult mobility, the range of slopes for macroinvertebrate groups often overlapped those of more mobile species. Hachich et al. (2015) found that, across 11 Atlantic Ocean archipelagos/islands (4-7516 $\mathrm{km}^{2} ; 20^{\circ} \mathrm{S}-$ $40^{\circ} \mathrm{N}$ ), the SAR slopes were greater for gastropods and seaweeds than for fish. These results agreed with findings from terrestrial systems, where higher slopes reflected greater effective isolation (Triantis et al. 2012). Given that there is a strong relationship between pelagic larval duration and dispersal distance (Siegel et al. 2003, Puritz et al. 2017), we explored the potential role of pelagic larval duration (Supplement 1; Supplements 1 to 7 are available at www.int-res.com/articles/suppl/m641p025_supp.pdf) and adult motility in driving inter-group differences in the relative insularity of macroinvertebrate assemblages in a large marine ecosystem. We addressed this relative insularity from the perspective of TIB
(SARs) and an investigation into the environmental drivers of inter-bank variation of assemblage structure within taxa/ species groups with varying motility and dispersal capacity.

For some assemblages of species, marine areas such as banks, reefs and seamounts can often function as 'islands' within a seascape of various other habitats (Rogers 1994, Dawson 2016, Meyer et al. 2016, Meyer 2017, Itescu 2019). Ocean currents (which can transport passive particles such as larvae) can play a significant role in connecting like habitats and establishing similar assemblages of species (Moritz et al. 2013). Variation in key habitat properties such as food availability, anthropogenic disturbance, current speed, habitat heterogeneity and temperature often leads to variation in assemblage structure in spite of flow connectivity and the innate dispersal capacity of marine organisms (Edgar et al. 2004, Mouquet et al. 2006, Rincón \& Kenchington 2016, Ashford et al. 2019). With a strong along-shelf current (NE-SW) potentially connecting the 10 offshore banks of the Scotian Shelf $\left(\mathrm{SS}_{\text {; }}\right.$ ranging in area from 500 to $10500 \mathrm{~km}^{2}$ on a $\sim 122000 \mathrm{~km}^{2}$ shelf between 43 and $46^{\circ} \mathrm{N}$ latitude; Fig. 1), we examined the relative degree to which oceanographic flows and physical habitat properties structured resident macroinvertebrate assemblages.

The SS and its 10 offshore banks are recognized as important and productive fishing grounds. For example, between 1986 and 2003, annual average landings of groundfish, invertebrates and small pelagics were 110000, 62000 and 125000 Mt, respectively (North Atlantic Fisheries Organization landings statistics; https://www.nafo.int/Data/STATLANT). The SS banks are considered ecological hotspots characterized by
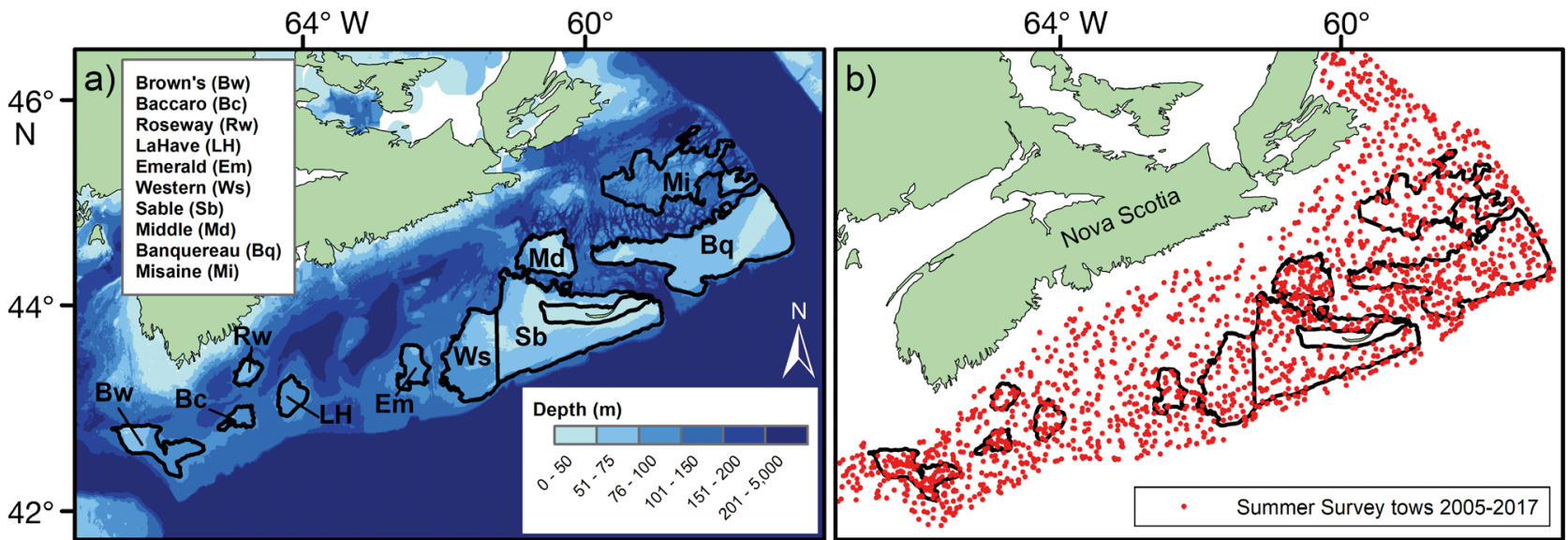

Fig. 1. (a) Bathymetry of the Scotian Shelf, Northwest Atlantic Ocean (provided by the Canadian Hydrographic Service), showing the 10 banks $(<100 \mathrm{~m})$. (b) Locations for all offshore (excluding the Bay of Fundy and Gulf of Maine) samples (tows) undertaken during the annual summer Fisheries and Oceans Canada ecosystem survey, 2005-2017. Bank polygons are from Doubleday \& Rivard (1981) 
relatively high diversity and productivity at both lower and upper trophic levels in comparison to surrounding areas (zooplankton: Tremblay \& Roff 1983, McLaren \& Avendaño 1995, Frank \& Shackell 2000; macroinvertebrates: Rowell \& Chaisson 1983, Roddick \& Lemon 1992, Shackell et al. 2013, Rincón \& Kenchington 2016; larval and adult fish: Frank \& Shackell 2001, Fisher \& Frank 2002, Shackell \& Frank 2003). These unique features of the banks have resulted in specific management measures designed to conserve commercially important species and habitats, and involving spawning season closures, gear restrictions and year-round fishery closures (Breeze et al. 2002). It is therefore appropriate to consider the banks as island-like assemblages for macroinvertebrates and to evaluate their conformation to predictions of the TIB as has been done in the past for the SS banks' fish assemblages (Frank \& Shackell 2001, Stortini et al. 2018).

By definition, the banks are relatively shallow (Fig. 1), which contributes to their higher productivity. Average depths range from 60 to $90 \mathrm{~m}$, while the mean depth of surrounding waters is $142 \mathrm{~m}$ (maximum depth of surrounding waters exceeds $300 \mathrm{~m}$ ). Substrates on the banks range from silt, mud and sand to gravel and cobbles, the latter in areas of strong tidal flows (Kostylev \& Hannah 2007). The nearestneighbor, maximum and average distance between the centroids of the banks is 90,640 and $280 \mathrm{~km}$, respectively. The mean circulation on the SS is dominated by the Nova Scotia Current $\left(\mathrm{NSC}_{i}\right.$ representative current of $0.05-0.01 \mathrm{~m} \mathrm{~s}^{-1} ; 0-50 \mathrm{~m}$ transport $\sim 300000 \mathrm{~m}^{3} \mathrm{~s}^{-1}$ ), which enters the NE shelf and flows SW into the Gulf of Maine after approximately 2-3 mo (Fig. 2; Sutcliffe et al. 1976, Chapman \& Beardsley 1989). The strong directionality of the NSC could affect the dispersal of eggs/larvae and connectivity among the banks, with a greater potential for the NE banks to seed those in the SW. A representative time scale of transport to nearby banks would be $10-20 \mathrm{~d}$. Most of the flow originates from the Gulf of St Lawrence, but exchange with warmer, more saline slope waters leads to increasing surface and bottom temperatures and salinities along its NE-SW path. The deep (approximately $150 \mathrm{~m}$ ) channel ('The Scotian Gulf') between Emerald and LaHave Banks is the main conduit of the onshore flow of continental slope waters. The NSC is generally stronger in the inner shelf (our Fig. 2; Brickman \& Drozdowski 2012) and, along with diffusive processes and retentive gyres (Loder et al. 1988, 2001, Cong et al. 1996), drives particle transport, including pelagic larvae (Suthers \& Frank 1991, Frank 1992, Reiss et al. 2000), within the mixed layer (0-25 m), potentially connecting and/or isolating bank communities. Recirculation features (Loder et al. 1988, Cong et al. 1996) act to retain larval fish on these banks and thus contribute to population structuring at this scale (Frank 1992).

The interaction of the NSC with the shelf topography, as well as exchange and mixing processes lead to different average temperatures, annual ranges of temperatures, mean salinities and chlorophyll a (chl a) concentrations over the banks. We examined the roles of these habitat characteristics/gradients, as well as bank area and habitat heterogeneity, in accounting for inter-bank variation of alpha diversity and assemblage structure of 3 taxa/species groups, namely members of the phyla Crustacea, Echinodermata and Mollusca (+ Cirripedia). We hypothesized that assemblages characterized by less motile species with shorter larval durations (relative to current transport [advection], bank separations and retention times), would be more insular, have steeper SAR slopes and be structured predominantly by local, physical habitat properties due to a greater likelihood that individuals will remain at or near their spawning location. By extension, we hypothesized that assemblages with

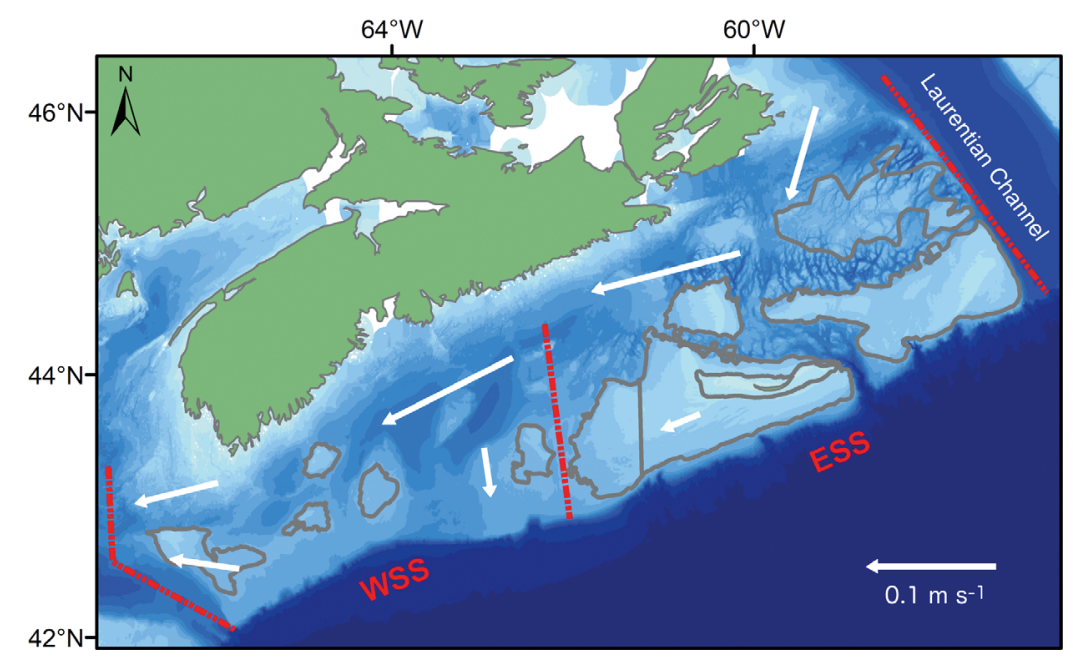

Fig. 2. Vector-averaged April-September currents (speed and direction indicated by linear scale and arrowheads, respectively) for the inner and outer shelf on the northeastern (ESS) and southwestern (WSS) halves of the Scotian Shelf (SS); ESS and WSS delineations are based on North Atlantic Fisheries Organization management units (Halliday \& Pinhorn 1990). Current vectors were based on 911 in situ, 0-30 m current meter observations (Supplement 1, Table S1.2) 
greater motility and longer larval durations would be more strongly interconnected and have weaker SARs. These assemblages may be structured predominantly by oceanographic habitat properties that could favor or limit colonization of larvae on the banks.

To test these hypotheses for the 10 banks, we (1) developed a detailed description of the physical and oceanographic bank habitat properties as well as the biomass distribution of the macroinvertebrate assemblages across the $\mathrm{SS}_{;}(2)$ compared SAR slopes among the 3 invertebrate groups; (3) assessed the extent to which physical and oceanographic habitat properties contributed to the variance in group-specific alpha diversity; and (4) assessed the extent to which physical and oceanographic habitat properties contributed to variability of group-specific assemblage structure based on the relative biomass of each species.

\section{DATA AND METHODS}

\subsection{Ecological data}

Consistent protocols for the identification, recording and quantification of invertebrates during the Fisheries and Oceans Canada annual July-August Scotian Shelf Research Vessel surveys began in 2005 and continue to the present day (Tremblay et al. 2007, DFO 2017). This stratified random survey was designed to sample representatively all depths across the shelf for the purpose of monitoring commercial stocks and ecosystem structure (survey began for fish and some commercially harvested invertebrates in 1970); 'strata' were defined as areas with similar depths (refer to Fig. S1.2 in Supplement 1). Individual strata are randomly sampled using a Western IIA otter trawl with a $19 \mathrm{~mm}$ mesh cod-end liner; the number of samples ('tows' covering $\sim 0.04 \mathrm{~km}^{2}$ ) per stratum is proportional to stratum area (Fig. 1b; Doubleday \& Rivard 1981). Macroinvertebrate species identities and species-specific total live wet biomass (a proxy for abundance given that some macroinvertebrates collected are colonial habitat-formers) are recorded for each tow (Tremblay et al. 2007). When species identities are unknown, biomasses are recorded at the genus, family or order level. All data were extracted for the strata corresponding to each bank (Fig. 1; Supplement 1, Fig. S1.2) for the 2005-2017 time period. For all analyses involving diversity estimates and species composition, records not identified at least to the genus level were removed; genus-level records were only included if there were no records identified to the species level within that genus. Polychaetes, jellies, hydrozoans and cephalopods were excluded due to limited and incomplete species identification. In all, 3781 of 8757 records $(\sim 43 \%)$ were removed from the larger invertebrate dataset (809 survey tows), leaving a total of 82 species/genera (4976 records from 800 survey tows). We considered: (1) crustaceans (29 species/genera of decapods), (2) echinoderms (27 species/genera of Ophiuroides and Asteroides) and (3) mollusks/Cirripedia (26 species/genera of gastropods, bivalves and barnacles). Although barnacles are members of the subphylum Crustacea, they were the only locally recorded infraclass (Cirripedia) of crustaceans with a sessile adult life stage; therefore, these animals were grouped with the mollusks.

\subsection{Habitat properties of the banks}

For each bank, we assembled physical and oceanographic habitat data considered relevant to the macroinvertebrate assemblages that were assessed, i.e. those which could influence group-specific alpha diversity and biomass-weighted assemblage structure. All data were extracted for the areas within the bank boundaries defined by the Fisheries and Oceans Canada annual summer ecosystem survey (Doubleday \& Rivard 1981; Fig. 1). Further details regarding the data sources, quantification and collinearity of all habitat properties are provided in Supplement 1.

\subsubsection{Physical habitat properties}

Physical habitat properties included bank area and habitat heterogeneity, both habitat properties purported to influence alpha diversity in MacArthur \& Wilson's (1967) TIB. Plan areas were calculated $\left(\mathrm{km}^{2}\right)$ using the stratum boundaries defined by Doubleday \& Rivard (1981) (Fig. S1.2 in Supplement 1). Habitat heterogeneity (Williams 1964) is likely to interact with bank area in driving patterns of group-specific alpha diversity and assemblage structure. Habitat heterogeneity for the 10 banks was characterized by the standard deviation (SD) of depths recorded at each survey tow from 2005 to 2017 . For the SS, depth SD is a good index of habitat heterogeneity because of the strong correlation between depth and sediment type (Kostylev \& Hannah 2007) and the associations of species distributions with preferred depth ranges (Perry \& Smith 1994). Banks with a larger depth SD would have a greater number of depth cat- 
egories, and potentially a greater number of sediment types, which could permit the coexistence of more species with different habitat preferences (e.g. Mahon \& Smith 1989), leading to a positive correlation with alpha diversity.

\subsubsection{Oceanographic habitat properties}

Oceanographic habitat properties included position of each bank's centroid relative to the NSC (distance to coast and distance along-shelf), measures of physical retention time, upper ocean $(0-50 \mathrm{~m})$ temperature and salinity, average bottom temperature, annual range of bottom temperatures, mean annual chl a concentration and mean peak (spring bloom, April-May) chl a concentration.

The perpendicular distance of each bank's centroid from the NE boundary of the shelf was measured to provide an index of a bank's position along the path of the NSC (Supplement 1). To account for differences of the NSC strength and other advective/diffusive processes between the inner shelf and outer shelf, and potential cross-shelf transport of larvae, we also measured the perpendicular distance of each bank's centroid from the coast (Supplement 1). Combined, these 2 metrics quantify the distance between bank centroids, and therefore the likelihood to share propagules. Similarity of assemblage composition was suspected to be highest on adjacent banks and to reflect the dominant circulation in the NE to SW direction.

Retention on the banks has been acknowledged as an important process affecting population growth (O'Boyle et al. 1984, Reiss et al. 2000). Cong et al. (1996) found that retention times were generally less than $15 \mathrm{~d}$ for the banks in March and April using a time-varying 3D shelf circulation model driven barotropically (constant with depth) by wind and baroclinically (variable with depth) by a seasonally averaged density field; the longest retention time was for Emerald Bank. Loder et al. (1988) used drifter data and ocean current meter data from 1979-1980 and April 1983 to March 1985 to estimate a retention time of 9-12 d for Brown's Bank. We quantified retention on all 10 banks using both a circulation model based on advective processes (WebDrogue v0.7, Hannah et al. 2000, 2001) and a method based on bank equivalent radius, water density and monthly current meter data (i.e. to account for both advective and diffusive processes). Using both approaches, retention on a bank was measured as the days after which only $37 \%$ of the original particles/ dye remained within the boundaries of the bank (efolding time, the same measure used by Cong et al. 1996). There was a positive relationship between the 2 measures of retention for the 10 banks with $\mathrm{r}^{2}=$ 0.46 (Fig. S1.4). A composite measure of retention was constructed as the average of the 2 measures, expressed in units of $\mathrm{SD}$, hereafter referred to as 'retention' and abbreviated as 'Ret' in figures.

Annual average temperature at the bottom and surface (upper $50 \mathrm{~m}$ ), annual range of bottom temperatures and annual average surface (upper $50 \mathrm{~m}$ ) salinity were quantified using Fisheries and Oceans Canada's CLIMATE database within the surveydefined boundaries of the banks. Bottom temperature characterizes the adult habitat and its suitability for settling larvae, while surface temperature influences survival, metabolism and growth rate of pelagic larvae. Due to impacts of temperature on physiology and survival (Pörtner 2002, Pörtner \& Gutt 2016), marine species distributions are often constrained by species-specific temperature tolerances (Pinsky et al. 2013). Additionally, annual ranges of bottom temperatures were suspected to influence alpha diversity; a bank with a wider range of temperatures throughout the year may host a greater variety of species than one with a small range because of temporal niche partitioning (e.g. Shurin et al. 2010). The high collinearity of surface and bottom temperatures and surface salinity (Fig. S1.1) allowed the 3 variables to be combined into a composite as the average of the 3 variables after normalizing, i.e. expressed in SD units. This composite variable is hereafter referred to as 'TS' or 'TS composite.' The annual range of bottom temperatures was not highly collinear with TS and was considered independently.

Chl a concentration is a good indicator of food availability for macroinvertebrates, which are mostly filter-feeders, scavengers and detritivores. In fact, the timing of spawning events for Pandalus borealis, a locally abundant shrimp species, was found to coincide with the spring bloom (Koeller et al. 2009). Further, food availability has been identified as a significant driver of peracarid biodiversity in the Northwest Atlantic in the vicinity of Flemish Cap and the Grand Banks off Newfoundland (Ashford et al. 2019). We hypothesized that banks with greater chl a (resource) concentrations year-round would support larger populations and possibly higher alpha diversity within each group. Chl a concentrations vary substantially with depth and location (Johnson et al. 2018). To develop a long-term climatology of chl $a$, we extracted all available in situ chl a concentration $\left(\mathrm{mg} \mathrm{m}^{-3}\right)$ records from Fisheries and Oceans Canada's BIOCHEM 
database within the survey-defined boundaries of the banks. Chl a concentrations were integrated (averaged) from 0 to $60 \mathrm{~m}$ (the shallowest average depth of the banks) for each bank; profiles were then averaged to estimate the spring peak (maximum during March-April) and the annual average depthintegrated chl a concentration.

To illustrate the spatial productivity patterns of the macroinvertebrate assemblages across the SS, we compared the biomass of the 3 groups (including all records, even those not identified to the genus level) on the banks relative to the surrounding deeper regions of the shelf; specifically, we calculated the average biomass of crustaceans, echinoderms and mollusks (+ Cirripedia) per survey tow across all bank strata, and compared to the average across all nonbank strata.

\subsection{Hypotheses and conceptual model}

The adult motility of the 3 species groups of interest differ. Many crustacean species, including American lobster Homarus americanus and snow crab Chionoecetes opilio, undergo seasonal migrations (up to $200 \mathrm{~km}$ for $H$. americanus, Pezzack \& Duggan 1986; 368 km for Gulf of St. Lawrence C. opilio, Biron et al. 2008). Adult echinoderms, more sessile than crustaceans, can exhibit 'tumbling' or 'balling' behavior, which allows them to exploit ocean currents (up to $90 \mathrm{~km} \mathrm{~d}^{-1}$; Hamel et al. 2019). Typically, echinoderms such as members of the classes Asteroidea (sea stars) and Ophiuroidea (brittle stars) can move as quickly or more quickly than mobile mollusks such as class Gastropoda (sea snails and slugs). Adult mollusks and Cirripedia, the most sessile of the groupings investigated, are typically attached to a substrate (bivalves and barnacles) or move slowly along the bottom (gastropods). To our knowledge, tumbling or balling behavior has not been observed in temperate mollusk species or in Cirripedia, but members of the family Pectinidae (scallops) are known to swim, using their adductor muscles, in response to perceived threats (Caddy 1968, Winter \& Hamilton 1985, Manuel \& Dadswell 1991). Given that most mollusk and Cirripedia species are, on average, sessile, we considered the group as a whole to be less motile than echinoderms at the adult stage. Therefore, we categorized the adult motility of the 3 groups as high (crustaceans), medium (echinoderms) and low (mollusks/Cirripedia).

Knowledge of the local season, duration and behavior of pelagic larval life stages of marine macroin- vertebrates is limited (Miller et al. 2010, Palumbi 2003, Meyer 2017); studies of population connectivity have largely been based on genetics (Shank 2010). However, it is increasingly recognized that larval durations can vary widely among species (Marshall \& Keough 2003, Bay et al. 2006, Shanks 2009), and that oceanographic processes can play a significant role in determining distance traveled despite species' biology (Baums et al. 2006, Shank \& Halanych 2007, Shanks 2009, Young et al. 2012). We used larval duration estimates available for macroinvertebrate species resident on the SS and similar temperate species from other regions (see Table S1.7), as well as general knowledge concerning the oceanographic processes of the region to derive hypotheses about the transport of macroinvertebrates among the SS banks. The available data indicate that the longest larval durations (as high as 90-240 d) occur within the crustacean group and the shortest durations (as low as 1-3 d) are within the mollusk/Cirripedia group (Fig. 3). Hamel \& Mercier (1996) provided the only local estimate of larval duration of 43-49 d within the echinoderm group based on experimental results from the Gulf of St. Lawrence for the common sea cucumber Cucumaria frondosa. However, larval durations of some temperate echinoderm species from other regions range from 14 to $155 \mathrm{~d}$, overlapping both the upper range of mollusk/ Cirripedia larval durations and the lower range of crustacean larval durations (Fig. 3; Table S1.7). Further compilations of experimental and in situ estimates

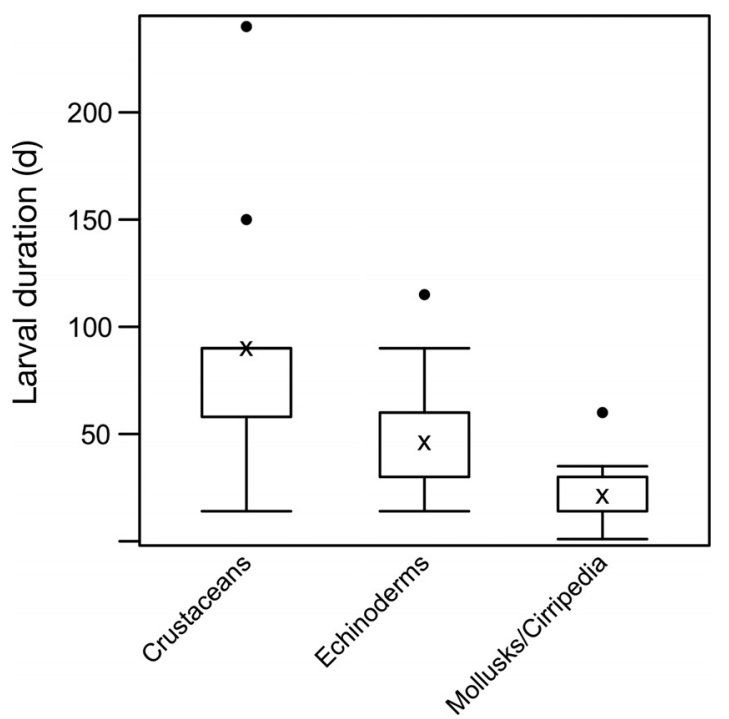

Fig. 3. Range and distribution of pelagic larval durations recorded for temperate species within each of the 3 species groups of interest. Mean values are shown as ' $x$ ', outliers as dots; boxes demarcate $25-75 \%$ of the distribution of values, whisker ends demarcate the lower $5 \%$ and upper $95 \%$ of the distribution of values 
of larval durations for various mollusk/Cirripedia, crustacean and echinoderm species in the Northeast Pacific by Shanks (2009) also suggested that mollusks/Cirripedia have the shortest (1-40 d), echinoderms mid-range (14-50 d) and crustaceans the longest (14-120 d) larval durations.

Larvae can be transported significant distances by continental shelf currents. A passive particle in a $0.1 \mathrm{~m} \mathrm{~s}^{-1}$ flow, typical of the inner SS (Fig. 2), could move $\sim 790 \mathrm{~km}$ in $91 \mathrm{~d}$ (mean of crustacean larval duration estimates; Fig. 3), potentially transiting the $\sim 700 \mathrm{~km}$ long shelf if cross-shelf transport, recirculation and diffusive processes are ignored. Therefore, we categorized crustaceans as having high larval dispersal capacity relative to the other 2 groups. With larval durations averaging $22 \mathrm{~d}$, corresponding to $190 \mathrm{~km} \mathrm{(} \mathrm{1/4} \mathrm{of} \mathrm{the} \mathrm{SS),} \mathrm{and} \mathrm{as} \mathrm{short} \mathrm{as} 1 \mathrm{~d}$ (Fig. 3), species in the mollusk/Cirripedia group were categorized as having low larval dispersal capacity. In the same currents, mollusk/Cirripedia larvae are more likely to be retained at spawning sites (estimated average e-folding retention times of 9-15 d for the SS banks; Loder et al. 1988, Cong et al. 1996) or will only reach nearby banks during 1 spawning season. Echinoderms, with a mean larval duration intermediate to the other 2 groups ( $52 \mathrm{~d}$, Fig. 3), might be transported $450 \mathrm{~km}(\sim 2 / 3$ of the SS); therefore, the echinoderms were categorized as having mid-range larval dispersal capacity.
This assessment of larval dispersal capacity is supported by numerous studies from rocky intertidal zones, subtidal zones, kelp forests, sandy beaches and soft bottoms in the Northeast Pacific. These studies have suggested that sessile, hard-bottom species, like many bivalves, are adapted for short-distance dispersal and self-recruitment (reviewed by Grantham et al. 2003). We did not consider the transport of buoyant pelagic eggs because of data limitations; however, combined passive transport of egg and larval stages could lead to greater dispersal. Further, the potential for intergenerational transport of species could not be estimated, although the 13 years of observations likely represent multiple generations of species within each group.

For the 10 banks, compositional variability could indicate the combined impact of along-shelf transport (relative to larval durations) and environmental filters (e.g. Cadotte \& Tucker 2017) such as temperature, salinity and productivity. Our expectations for the 3 groups are summarized in Fig. 4. With the dominant NSC, the background of along-shelf gradients in bank habitat properties (filters), and the relative adult motility and larval dispersal capacities of species groups, we expected the bank crustacean assemblages to be the most similar, followed by the echinoderms, and lastly the mollusks/Cirripedia. If crustacean larvae can transit the entire shelf in 1 spawning season and adults can move shelf-scale

\section{Southwest Northeast}

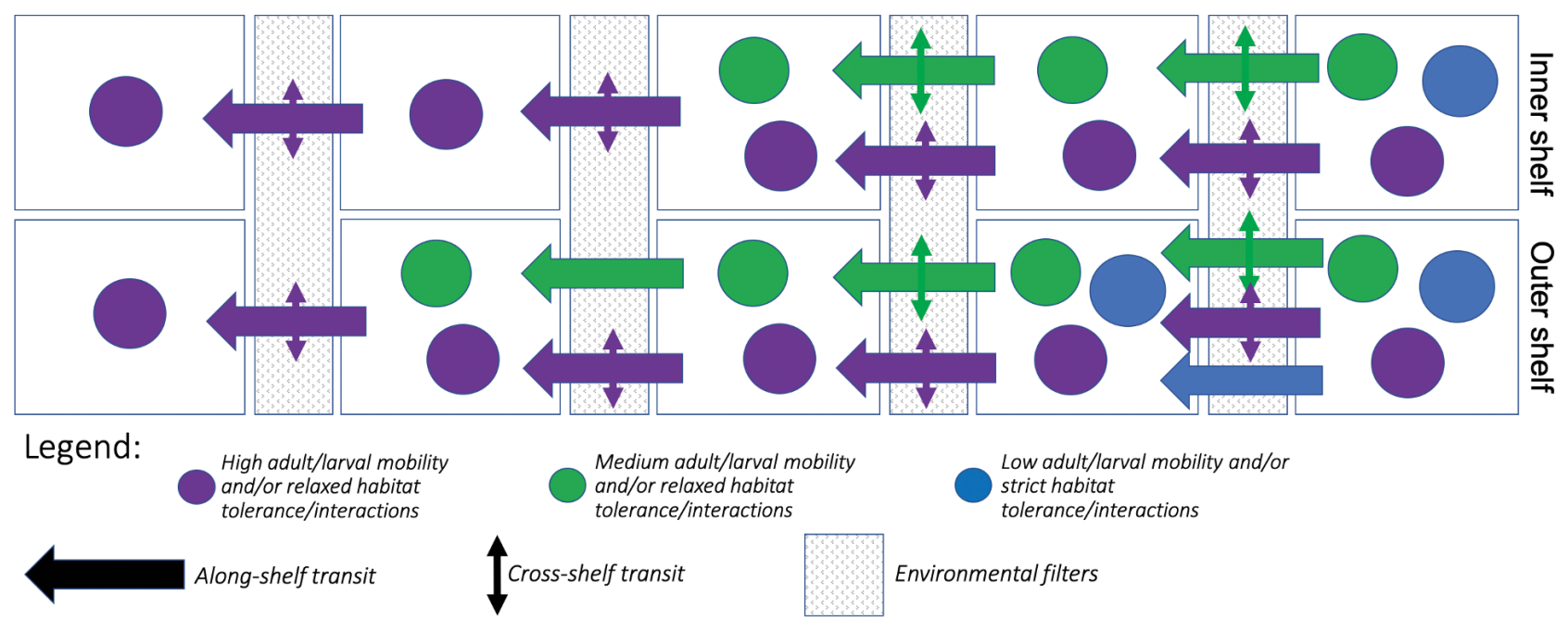

Fig. 4. Hypothesized impact of the Nova Scotia Current and environmental filtering of macroinvertebrate communities along NE to SW flow (dots; colors represent species groups with different traits) across the Scotian Shelf banks (white squares). The transit distance of species is expected to be proportional to their group-specific dispersal capacities at adult and larval life stages and current strength. Other environmental filters (represented by hatched boxes between banks), e.g. habitat preferences/tolerance and species interactions (Cadotte \& Tucker 2017), could be important secondary determinants of species composition and relative biomasses on the banks 
distances, differences in assemblage structure among the banks should occur only when variations in habitat properties strongly affect species' abundances/ relative biomass through different tolerance and/or competitive or predator-prey interactions. On the other hand, short larval durations could prevent mollusk/Cirripedia larvae from reaching even the most proximate banks.

\subsection{SARs}

The SARs for each group were based on species presence/absence records from the 2005-2017 surveys. All records not identified to at least the genus level were removed. The absence of clearly defined asymptotes of species richness for 5, 3 and 5 of the 10 banks for crustaceans, echinoderms and mollusks/ Cirripedia, respectively, indicated that the groupspecific species richness of these banks has not yet been completely sampled (Supplement 2 ). We therefore estimated all alpha diversity values using the Jackknife1 estimator (Smith \& van Belle 1984). This estimator accumulates species richness across randomly selected tows and then adds an estimated number of species that were likely undetected. The estimated number of undetected species $\left(a_{1} \frac{(n-1)}{n}\right)$ is based on the number of species that were sampled only once during the selected period ( $a_{1}$, Eq. 1). These are species that are either difficult to capture or are at such low abundance as to be rarely observed. Such species were most evident within the mollusk/Cirripedia group (Supplement 3). Alpha diversity was estimated as the cumulative number of species (plus those undetected), as:

$$
S_{\mathrm{e}}=S_{\mathrm{o}}+\left\{\mathrm{a}_{1} \frac{(\mathrm{n}-1)}{\mathrm{n}}\right\}
$$

where $S_{\mathrm{e}}$ is the estimated alpha diversity per cumulative number of survey tows (n), $S_{0}$ is the number of species observed per $n$, and $a_{1}$ is the number of species only observed in 1 of $\mathrm{n}$ tows. Total alpha diversity per bank, per regime, was calculated as the cumulative $S_{\mathrm{e}}$, when $\mathrm{n}=\mathrm{N}$ (total number of tows). The sampling variance associated with estimates of alpha diversity was calculated, according to Smith \& van Belle (1984), as:

$$
\operatorname{var}_{S_{\mathrm{e}}}=\left(f_{1}-\frac{a_{1}^{2}}{\mathrm{~N}}\right) \frac{\mathrm{N}-1}{\mathrm{~N}}
$$

where $a_{1}$ is the number of species observed only once in $\mathrm{N}$ number of tows, and $f_{1}$ is the total number of tows with 'singleton' species (i.e. those counted in $a_{1}$ ).
The bank-specific Jackknife1 alpha diversity estimates and bank areas were $\log _{10}$-transformed in SAR models (see Supplement 2 Section 2.4 for details). The group-specific SARs took the following form:

$$
S_{\mathrm{e}}=k+z\left[\log _{10}(A)\right]
$$

where $S_{e}$ is the log-transformed Jackknife estimated cumulative alpha diversity per bank, $k$ is the estimated intercept, $z$ is the slope, and $A$ is bank area measured in $\mathrm{km}^{2}$. Each $S_{\mathrm{e}}$ was weighted by the inverse of its corresponding variance $\left(1 / \operatorname{var}_{S_{\mathrm{e}}}\right)$, such that alpha diversity estimates with larger error were weighted less heavily in the models. The derived SARs were compared among the 3 species groups; our expectation was that the slope of the SAR would be highest for mollusks/Cirripedia (the least mobile), lower for echinoderms and lowest for crustaceans (the most mobile).

\subsection{Other environmental predictors of alpha diversity}

Given the along-shelf variation of many bank habitat properties including area (see Section 3.1), we explored whether any habitat properties could account for similar or more variation in group-specific alpha diversity than bank area alone. The purpose was to identify potential contributing factors to the SAR (e.g. habitat heterogeneity), or incidences where other habitat properties counteract or negate the influence of area. Univariate correlations between groupspecific alpha diversity and habitat characteristics (Fig. S1.1) were evaluated in order to formulate the initial linear models of alpha diversity with all of the most important $(\mathrm{r}>0.5)$ habitat properties. Graham (2003) found that a variance inflation factor (VIF; Fox \& Monette 1992) as low as 2 could have a significant impact on the partitioning of variance among predictor variables in a model; high importance placed on one variable might only be due to its collinearity with another. Therefore, when 2 collinear variables had VIF $>2$, cluster-independent sequential regression was applied; the residuals of the regression of these 2 variables were used as the second variable (as described by Dormann et al. 2013). All possible combinations of the most important habitat properties were tested as predictor variables; models that included only 1 variable were also tested. Stepwise Akaike's information criterion adjusted for small sample sizes (AICc; Mazerolle 2019) model selection was employed to identify the best model (lowest AICc) of alpha diversity for each group. Environmental predictors of alpha diversity were considered a significant improvement from 
the SAR only when $\triangle$ AIC $>2$ (Burnham \& Anderson 2002). Alpha diversity estimates were weighted by the inverse of their standard error $(+1)$. Where the Jacknife1 estimates were equal to the raw species counts (e.g. for mollusks/Cirripedia on LaHave and Emerald Banks: no species occurred in only 1 survey tow), the corresponding standard error was zero, therefore the weight was equal to 1 , producing a lack of error bars (see Figs. 8 \& 9).

\subsection{Group-specific assemblage structure and its environmental predictors}

Assemblage structure was defined by the relative biomass of species (rather than presence/absence, which defines species composition); this approach accounted for the important influence of high-biomass species on assemblage structure. Consequently, the resulting analysis could largely reflect inter-bank differences in the biomass of the dominant (4-9) species (Supplement 3).

We evaluated differences in species-specific biomass per tow (within taxa/groups), Bray-Curtis assemblage similarity index $(\mathrm{BCSI}=1-\mathrm{BCI}$, where $\mathrm{BCI}$ is the Bray-Curtis dissimilarity index; Oksanen et al. 2019; range 0-1, where 1 indicates identical communities, 0 indicates no commonalities in species' relative biomasses; Supplement 3) and average total groupspecific biomass across the banks. We then assessed the relative contribution of habitat characteristics to observed group-specific assemblage structure (relative biomass of species) using a sequential regression approach to canonical correspondence analysis $(\mathrm{CCA}$; Palmer 1993, Legendre \& Legendre 2012). CCA constrains the axes of variation in assemblage structure among banks with chosen environmental covariates (expressed as vectors). CCA models for each group were populated with all possible combinations of environmental covariates; sequential regression was used when collinear variables produced a VIF > 2 (as in Section 2.5). Stepwise model selection was employed to reduce the CCA model to include only covariates that contributed significantly to overall inertia (chi-squared) of the model and gave the lowest AICc.

\section{RESULTS}

\subsection{Habitat properties of the banks}

The physical properties of the banks had distinct NE to SW gradients (Fig. 5a; Supplement 1). Bank area and habitat heterogeneity (Depth SD) were highly correlated (Fig. 5a; $r=0.68$ linear, $r=0.81$ semi-log $[\ln$ (Area) $] ;$ Supplement 1); both were generally higher in the NE (Western, Sable, Middle, Banquereau, Misaine), and lower in the SW (Emerald, LaHave, Roseway, Baccaro), except for Brown's Bank.

Many oceanographic properties exhibited NE-SW gradients (Fig. 5b). NE banks tended to be farther from the coast than the SW banks, potentially experiencing a weaker NSC (Fig. 2). With the exceptions of Baccaro and Roseway Banks (short retention times) and Sable Bank (long retention time), retention times did not vary substantially among the other 7 banks. The weak tendency for longer retention times in the NE could partly reflect bank area. Retention times were between 1 and $20 \mathrm{~d}$, within the range of earlier studies (Loder et al. 1988, Cong et al. 1996). These estimates were short compared to the majority of compiled larval durations (Fig. 3). Along-shelf gradients in TS water properties were evident, with colder, less variable temperatures and lower salinities on the NE banks compared to the SW banks. There was also an overall negative NE-SW gradient of the depth-integrated (averaged from the surface to $60 \mathrm{~m}$ ) mean and peak chl a concentrations.

The habitat properties and the relationship among the banks were summarized by the leading components of a principal component analysis (PCA, Fig. 5c). The first 2 components (PCA1 and PCA2) of the habitat properties captured 55 and $18 \%$ of the overall variance, respectively. PCA1 accounted for $50 \%$ or more of variance for 6 of the 9 habitat properties, with high amplitudes corresponding to larger areas, greater habitat heterogeneity (higher depth SD), greater distances from the coast and proximity to the NE boundary of the shelf, long retention times, colder/less saline conditions, small annual range of bottom temperatures and high chl a concentrations. This led to the banks separating into 2 groups, one in the SW and one in the NE (a bimodal distribution of eigenvector amplitudes for PCA1), with a transition at Emerald and Western Banks. The strong association of habitat properties indicated a high degree of collinearity.

On average, the banks had almost double the total macroinvertebrate biomass per unit area (5.3 $\pm 0.7 \mathrm{~g} \mathrm{tow}^{-1}$ ) compared to the surrounding, deeper regions of the shelf $\left(2.7 \pm 0.2 \mathrm{~g} \mathrm{tow}^{-1}\right.$; Fig. $\left.6 \mathrm{a}\right)$; tows of highest biomass generally occurred on the banks, with the exception of the deeper channels 
a) Physical habitat properties
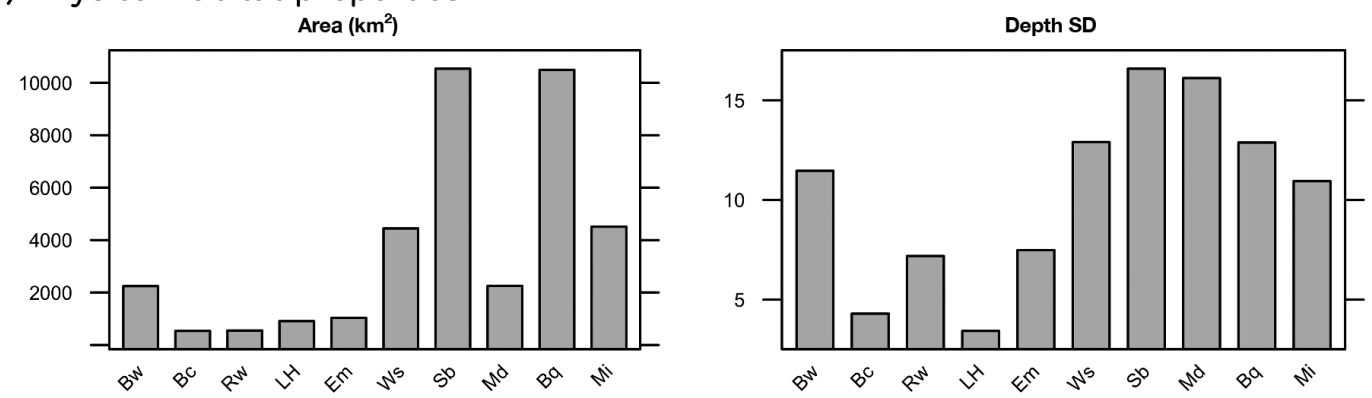

b) Oceanographic habitat properties
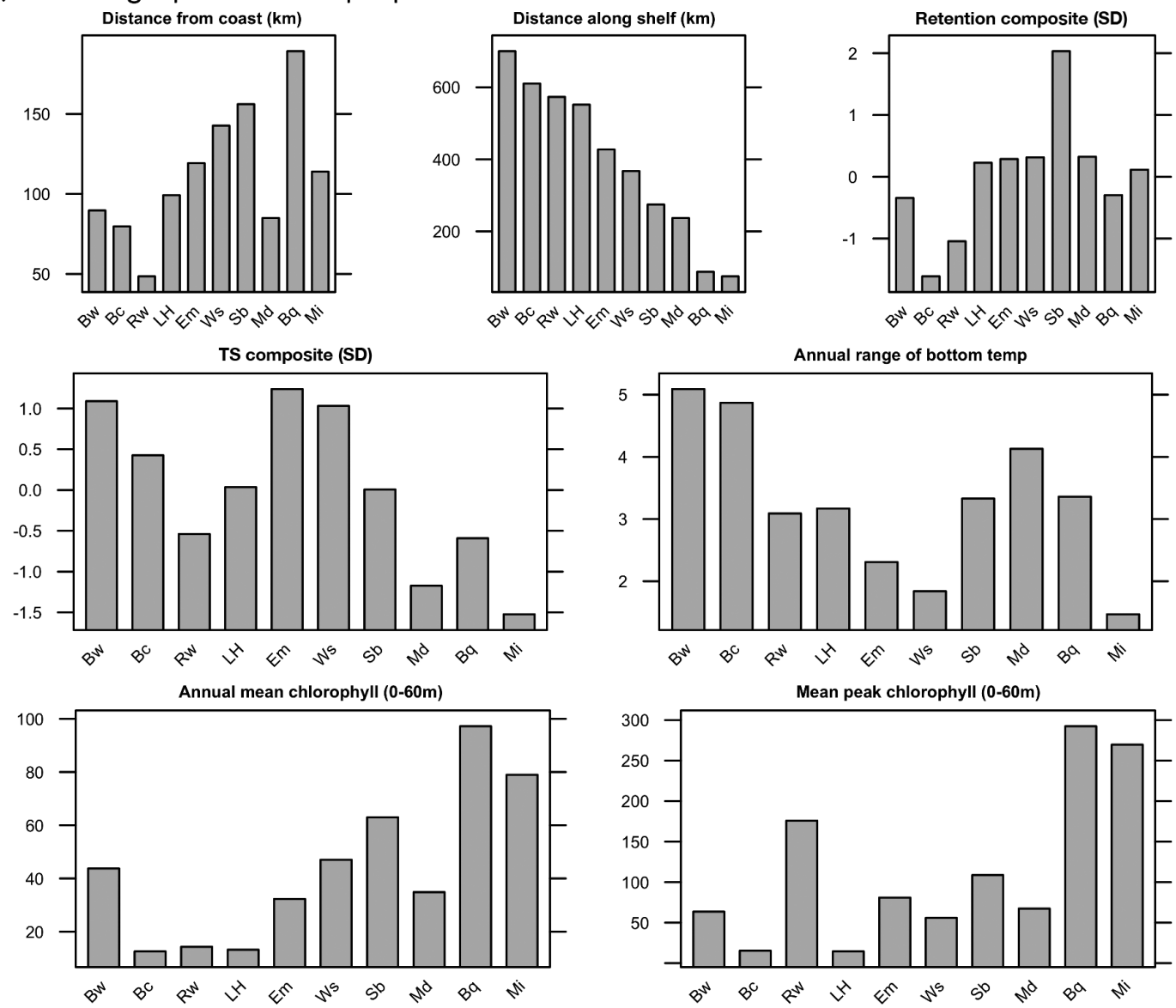

c) Principal Component Analysis of habitat properties
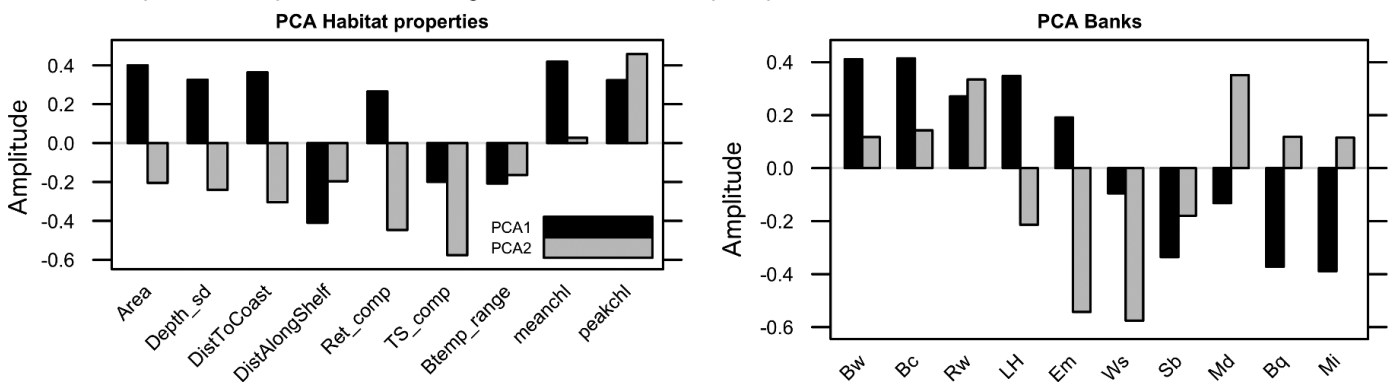

Fig. 5. (a) Physical bank habitat properties, (b) oceanographic bank habitat properties and (c) eigenvector amplitudes (for habitat properties [left] and banks [right]) resulting from a PCA. In all plots where applicable, banks are listed on the $x$-axis from SW (Brown's) to NE (Misaine); abbreviations of bank names as in Fig. 1. Note that the flow of the NSC is NE to SW (right to left) 

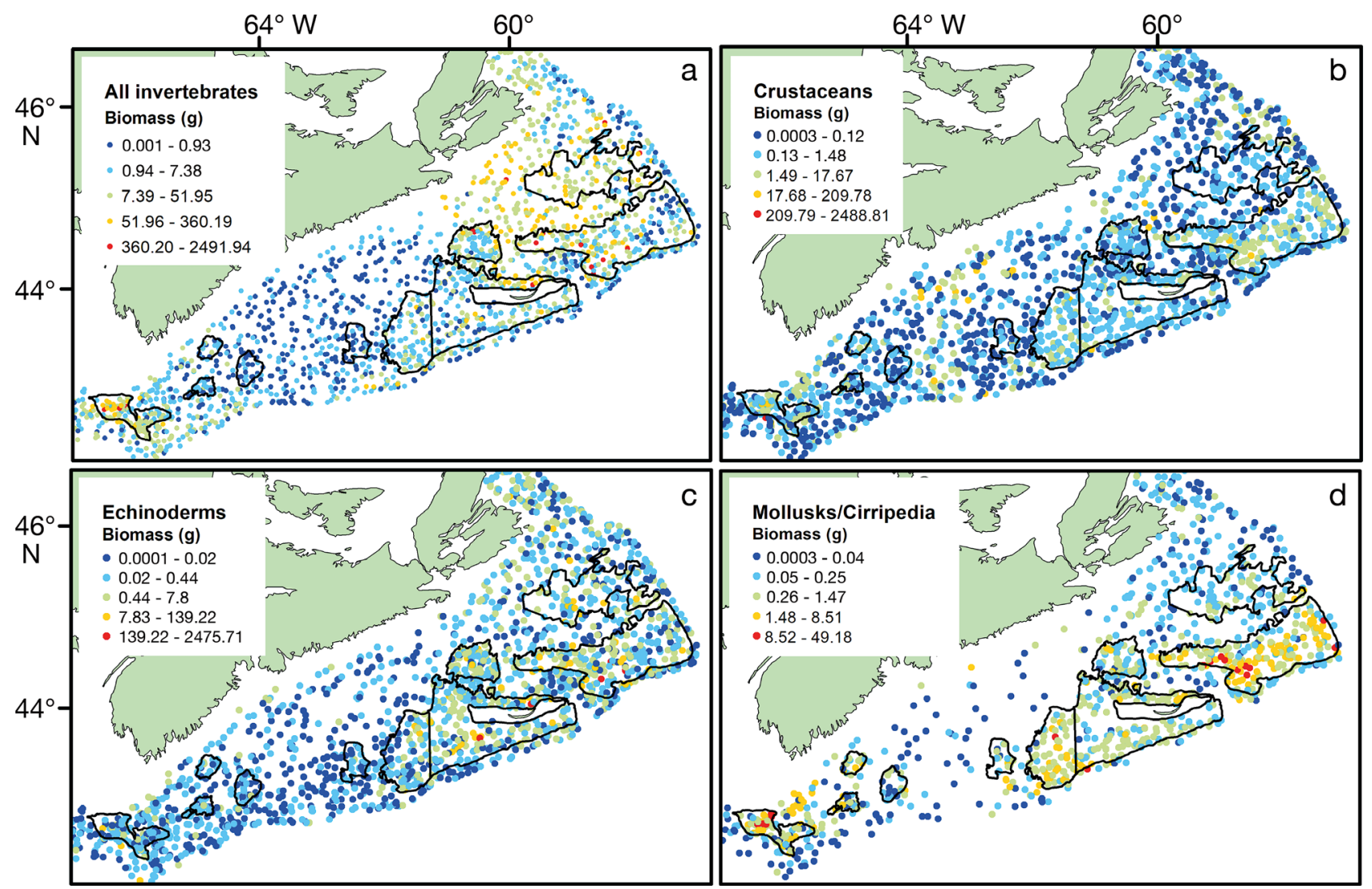

Fig. 6. Total biomass (g) per survey tow for (a) all macroinvertebrates (sum of all 3 groups) and for each group individually: (b) crustaceans, (c) echinoderms, (d) mollusks/Cirripedia. Survey tow records of zero biomass were excluded for clarity. Geometric interval scaling was used for color-coding

between Misaine, Middle and Banquereau Banks. The banks had significantly more echinoderm (8.5 $\pm 1.5 \mathrm{~g} \mathrm{tow}^{-1}$ on banks compared to $1.1 \pm 0.2 \mathrm{~g}$ tow $^{-1}$ off banks; Fig. 6c) and mollusk/Cirripedia $\left(0.8 \pm 0.1 \mathrm{~g} \mathrm{tow}^{-1}\right.$ on banks compared to $0.3 \pm 0.1 \mathrm{~g}$ tow $^{-1}$ off banks; apparent in Fig. 6d) biomass per unit area. On the other hand, the average crustacean biomass was $35 \%$ higher in off-bank areas $(4.7 \pm$ $\left.0.4 \mathrm{~g} \mathrm{tow}^{-1}\right)$ compared to on the banks $(3.5 \pm 0.4 \mathrm{~g}$ to $^{-1}$; Fig. 6b). A partitioning of the crustacean group into 2 groups (Supplement 4), made apparent that this was due to shrimps (largely Pandalus, Sclerocrangon, Argis and Lebbeus species), which had greater biomass in deeper regions $(6.9 \pm 0.8 \mathrm{~g}$ tow $^{-1}$ ), particularly the deeper channels between Misaine, Middle and Banquereau Banks, than on banks $\left(3.5 \pm 0.6 \mathrm{~g} \mathrm{tow}^{-1}\right)$. Species within the infraorder Brachyura (crabs) and family Nephropidae (lobsters) tended to have a slightly higher biomass on banks $\left(3.5 \pm 1 \mathrm{~g} \mathrm{tow}^{-1}\right)$ compared to deeper regions $\left(2.8 \pm 0.5 \mathrm{~g} \mathrm{tow}^{-1}\right.$; Supplement 4$)$. These results suggested that, with the exception of shrimps, the banks represent the most important habitat for the benthic stages of macroinvertebrates on the SS.

\subsection{SARs}

Both raw species richness (Fig. 7a) and Jackknife1 alpha diversity estimates (Fig. 7b) had a greater range for mollusks/Cirripedia than the other 2 groups. The range of alpha diversity estimates for the 10 banks was double for mollusks/Cirripedia (21 species) compared to crustaceans (11 species) and echinoderms (10 species) (Fig. 7b). Mollusks/Cirripedia, the least mobile group, exhibited a statistically significant $(\alpha=$ $0.05)$ SAR slope $(z)$ of $0.64(95 \%$ CI $=0.19-1.09$; Fig. 8c). The slopes of the crustacean and echinoderm SARs were small in comparison. The slope of the crustacean SAR $(z=0.06 ; 95 \% \mathrm{CI}=-0.02$ to 0.14$)$ was not significantly different from 0 , and the slope of the echinoderm SAR $(z=0.09 ; 95 \% \mathrm{CI}=0.01-0.17)$ was only marginally different from 0 . The SAR slopes did not differ significantly between crustaceans and echinoderms (Fig. 8a,b). 

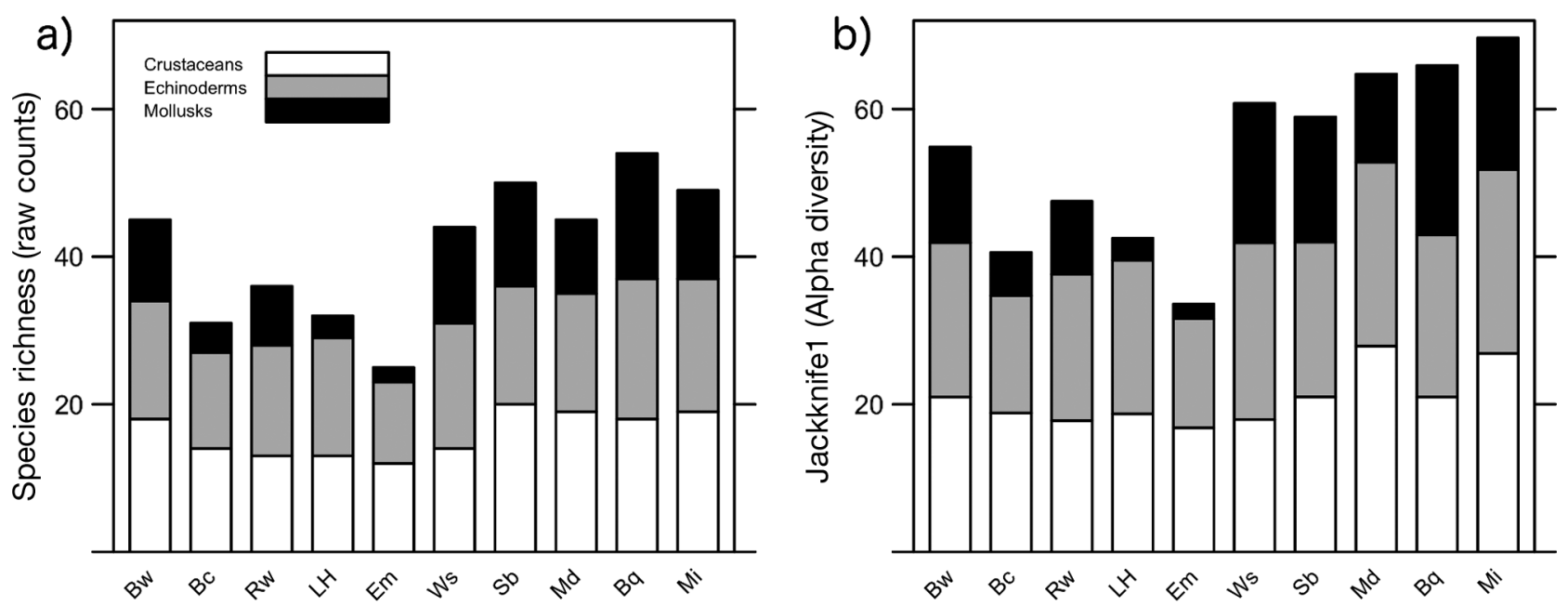

Fig. 7. (a) Raw species counts and (b) alpha diversity estimates for crustacean (white), echinoderm (grey) and mollusk/Cirripedia (black) groups across the banks listed from SW (Bw) to NE (Mi). Abbreviations of bank names as in Fig. 1

a) Crustaceans

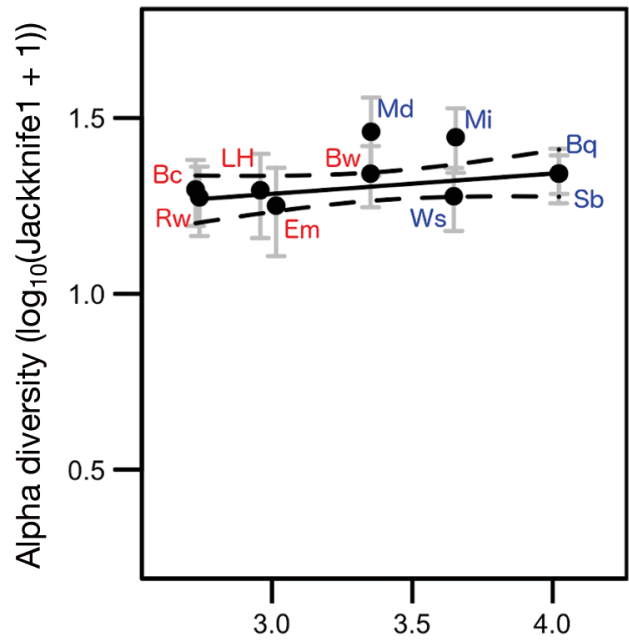

b) Echinoderms

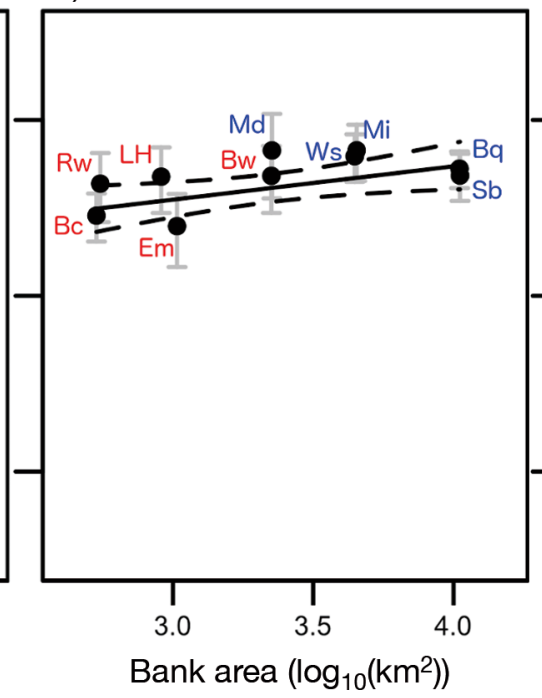

c) Mollusks/Cirripedia

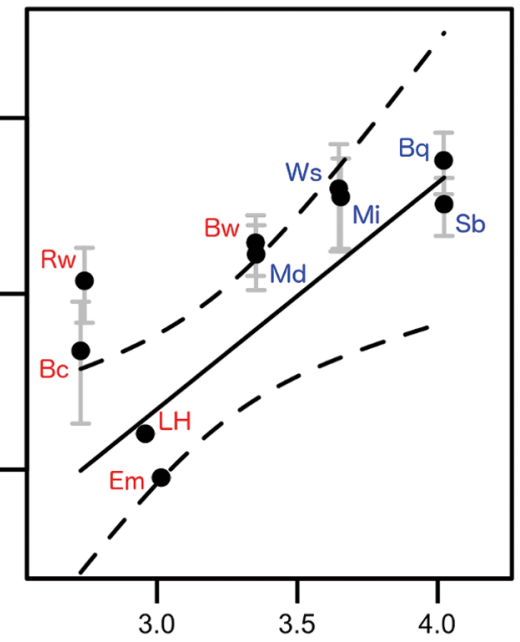

Fig. 8. Species-area relationships (SARs) for (a) crustaceans, (b) echinoderms and (c) mollusks/Cirripedia. Error bars represent the $95 \%$ CI of each alpha diversity estimate (dots). Dashed lines represent the $95 \%$ CI of the SAR fit (solid line). Abbreviations of bank names as in Fig. 1, color-coded by geographic location (blue $=\mathrm{NE}$, red $=\mathrm{SW}$ )

\subsection{Environmental predictors of alpha diversity}

Bank area was not a significant predictor of crustacean and echinoderm alpha diversity; therefore, the roles of environmental variables were explored. The TS composite index (Fig. 5b) accounted for $51 \%$ of the variance in crustacean alpha diversity (Fig. 9a), corresponding to a 7-species decrease from the coldest/least saline bank (Misaine) to the warmest/most saline bank (Emerald). This was an improvement from the SAR $(\triangle \mathrm{AICC}=5.05$; Table 1$)$, which accounted for only $19 \%$ of the variance in crustacean alpha diversity (Fig. 8a). This composite index is significantly correlated ( $\mathrm{r}=0.63$ ) with distance alongshelf, reflecting warming and increasing salinity along the NSC (Fig. 5c, Supplement 1), which is part of the Arctic-to-equatorward flow on the Canadian Atlantic coast (Loder et al. 1998). The relationship with TS may reflect cold-water species reaching the southern limits of their habitat range.

Habitat heterogeneity (depth SD) accounted for the same proportion (39\%) of variation in echinoderm alpha diversity (Fig. 9b) as area (Fig. 8b). For mollusks/ Cirripedia, habitat heterogeneity accounted for $5 \%$ 
a) Crustaceans

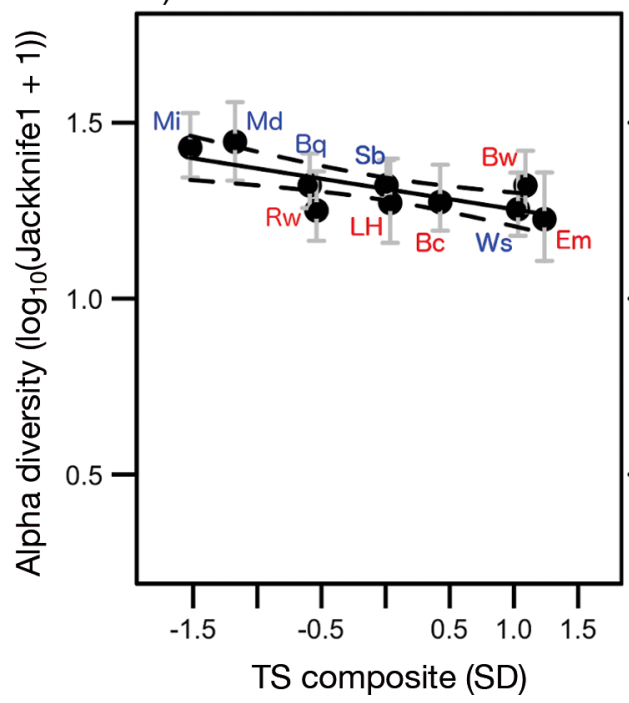

b) Echinoderms

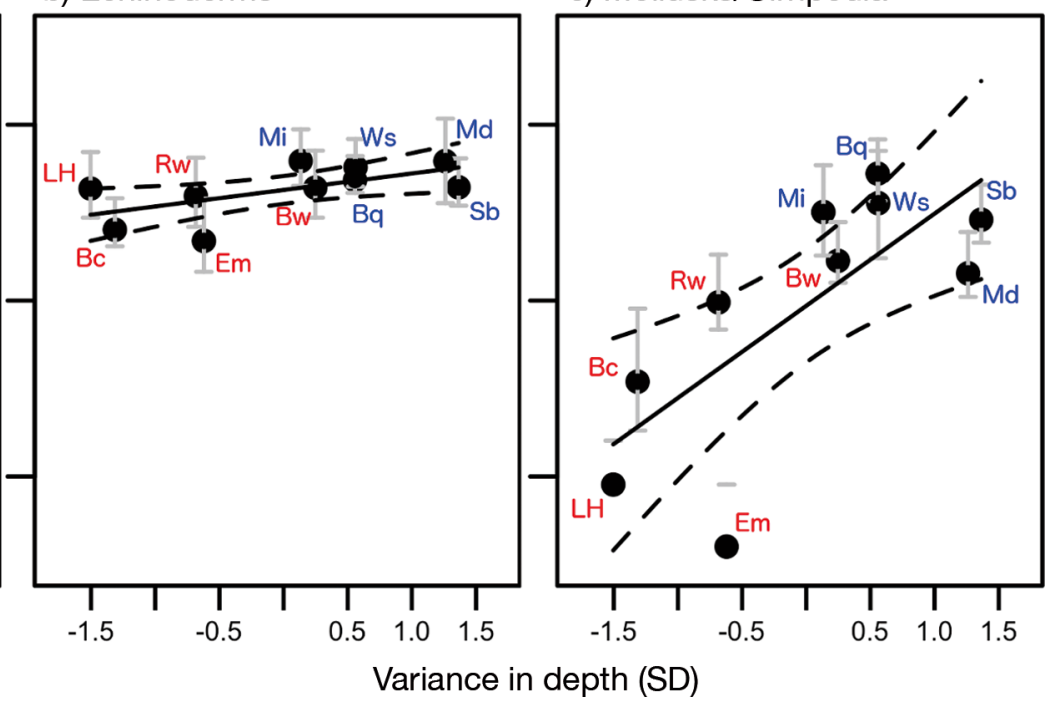

Fig. 9. Relationships between alpha diversity ( $\log _{10}$-transformed) and its best environmental predictor (units of standard deviation, SD) for (a) crustaceans, (b) echinoderms and (c) mollusks/Cirripedia. Abbreviations of bank names as in Fig. 1, color-coded by geographic location (blue $=\mathrm{NE}$, red $=\mathrm{SW}$ ). TS: temperature/salinity

Table 1. Comparison of group-specific species-area relationships (SARs) to models with best alternative environmental predictors. Akaike's information criterion adjusted for small sample sizes (AICc) was used in model selection (lowest AICc indicated best model); $\triangle \mathrm{AICC}$ values $>2$ indicated a vast improvement of one model from the other. TS: temperature/salinity composite; SD: standard deviation

\begin{tabular}{|c|c|c|c|c|c|c|c|c|c|c|}
\hline \multirow{2}{*}{ Group } & \multicolumn{4}{|c|}{ - SAR } & \multicolumn{5}{|c|}{ - Best environmental model } & \multirow{2}{*}{$\Delta \mathrm{AICC}$} \\
\hline & $\mathrm{R}^{2}$ & $z$ & $\mathrm{p}$ & $\mathrm{AICC}$ & Predictor & $\mathrm{R}^{2}$ & z & $\mathrm{p}$ & $\mathrm{AICc}$ & \\
\hline Crustaceans & 0.19 & 0.06 & 0.21 & -18.40 & TS & 0.51 & -0.05 & $<0.05$ & -23.45 & 5.05 \\
\hline Echinoderms & 0.39 & 0.09 & 0.05 & -18.54 & Depth SD & 0.39 & 0.05 & 0.05 & -18.58 & 0.04 \\
\hline Mollusks/Cirripedia & 0.49 & 0.64 & $<0.05$ & 13.59 & Depth SD & 0.54 & 0.29 & $<0.05$ & 12.65 & 0.94 \\
\hline
\end{tabular}

more inter-bank variation in alpha diversity than area (Fig. 9c), but $\triangle \mathrm{AICC}=0.94$, implying that the environmental model was not a significant improvement from the SAR (Table 1). The limited improvement from the SAR in models with habitat heterogeneity as the primary predictor may reflect, in part, the correlation of this variable with bank area (recall: $r=0.68$ linear, $r=0.81$ semi- $\log [\ln ($ Area $)]$.

\subsection{Group-specific assemblage structure and its environmental predictors}

The distribution of biomass among these assemblages had strong spatial gradients (Fig. 10). Alongshelf biomass gradients (decreasing to the SW) were strong for crustaceans (omitting Brown's) and echinoderms, and weaker for mollusks/Cirripedia (Fig. 10a-c). Rather than exhibiting gradients in species' biomass, half (13/26) of the mollusk/Cirripedia species present on the NE banks were not observed on the SW banks (Fig. 10c). Most $(75 \% ; 21 / 28)$ crustacean species in the NE were observed in the SW, but $14(67 \%)$ declined in biomass (Fig. 10a). With increasing NE-SW temperatures, there were decreases in biomass (mean per tow) of some cold-water crustacean species, e.g. Aesop shrimp Pandalus montagui, snow crab, Arctic argid Argis dentata and Arctic lyre crab Hyas coarctatus (Fig. 10a; Supplement $3)$. This result strengthens our finding that TS properties were the most important predictors of crustacean alpha diversity; more species seem to favor the colder NE banks as typified by their higher biomass. From the NE to SW, echinoderms had the strongest biomass gradient (Fig. 10b) and a loss of 9 of 27 species (Fig. 10b).

These along-shelf gradients in biomass led to 2 distinct crustacean complexes: one in the SW (Baccaro, Roseway, LaHave, Emerald; average BCSI $=0.62$ ) and another in the NE (Misaine, Banquereau, Sable, 


\section{a) Crustaceans}

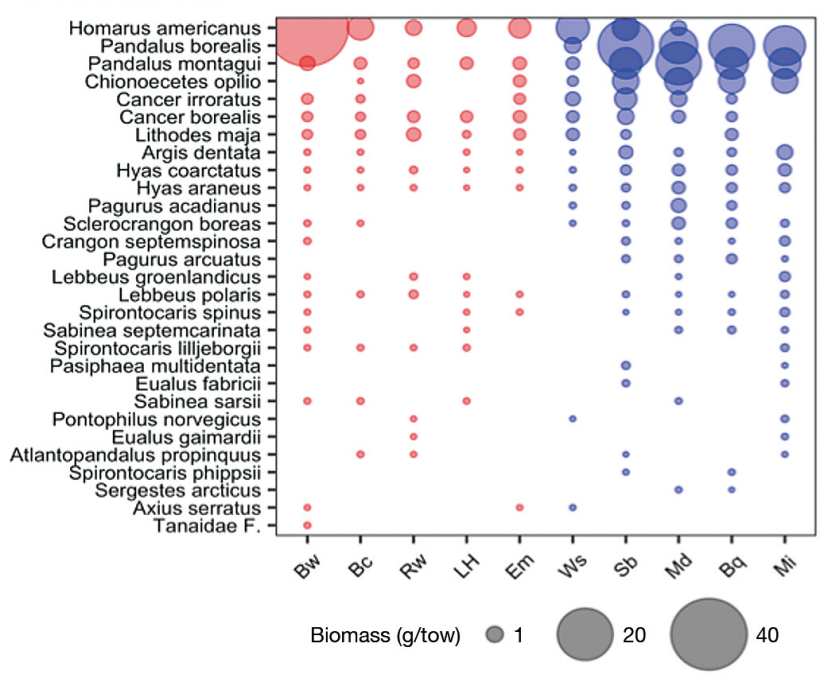

\section{b) Echinoderms}

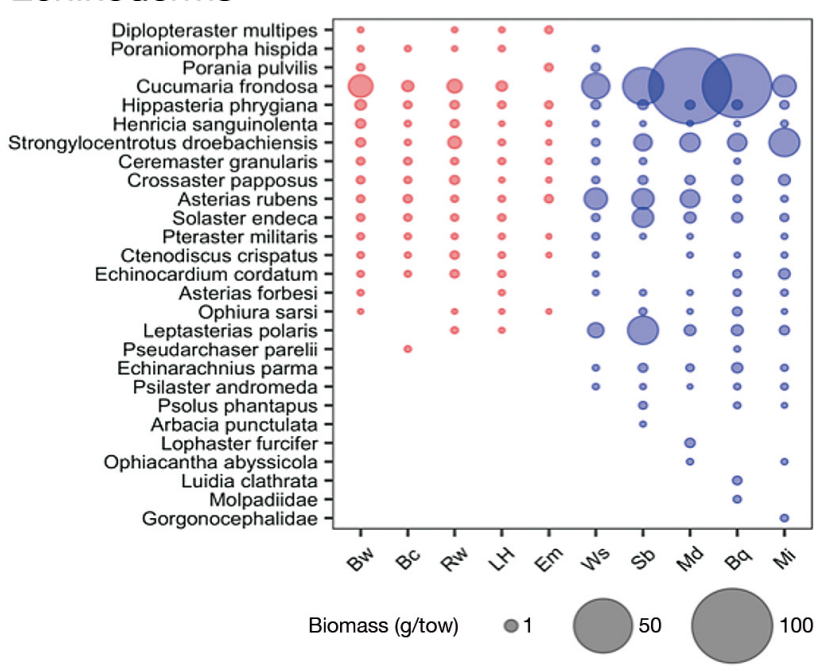

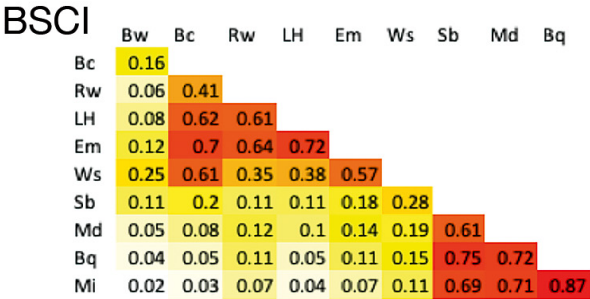

Sum

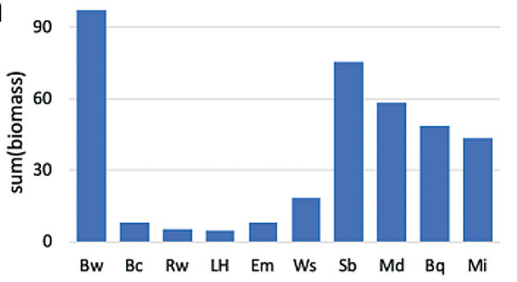

$\mathrm{BSCl}$

$$
\begin{array}{l|l|l|l|l|l|l|l|l|l|l|l|l}
\text { Bc } & 0.26 & & & & & & & & \\
\text { Rw } & 0.43 & 0.44 & & & & & & & \\
\text { LH } & 0.19 & 0.74 & 0.38 & & & & & & \\
\text { Em } & 0.08 & 0.33 & 0.1 & 0.21 & & & & & \\
\text { Ws } & 0.56 & 0.13 & 0.21 & 0.09 & 0.05 & & & & \\
\text { Sb } & 0.27 & 0.05 & 0.13 & 0.03 & 0.01 & 0.52 & & & \\
\text { Md } & 0.11 & 0.02 & 0.05 & 0.01 & 0.01 & 0.21 & 0.37 & & \\
\text { Bq } & 0.16 & 0.03 & 0.08 & 0.02 & 0.01 & 0.21 & 0.43 & 0.8 & \\
\text { Mi } & 0.49 & 0.1 & 0.29 & 0.08 & 0.02 & 0.37 & 0.3 & 0.16 & 0.22 \\
\hline
\end{array}
$$

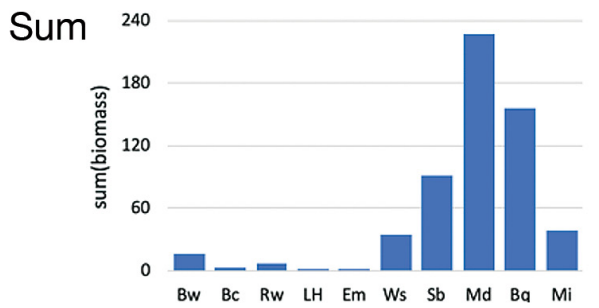

\section{c) Mollusks/Cirripedia}

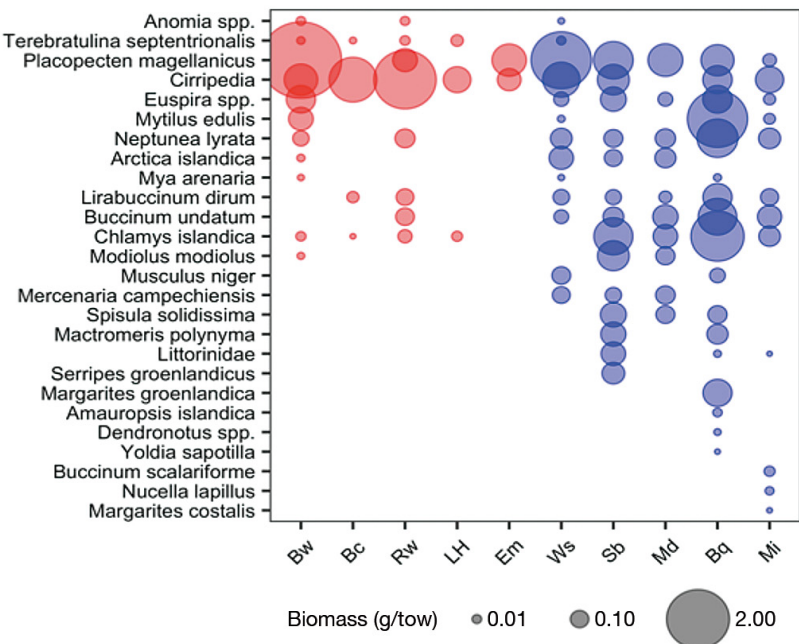

\section{$\mathrm{BSCl}$}

Bc 0.16

\begin{tabular}{l|l|l|} 
Rw & 0.22 & 0.6 \\
\hline
\end{tabular}

\begin{tabular}{lll|l|l} 
LH & 0.13 & 0.41 & 0.22
\end{tabular}

$\begin{array}{llllll}\text { Em } & 0.26 & 0.22 & 0.26 & 0.38\end{array}$

\begin{tabular}{l|l|l|l|l|l|} 
Ws & 0.62 & 0.29 & 0.37 & 0.17 & 0.36
\end{tabular}

\begin{tabular}{l|l|l|l|l|l|l|l}
$\mathrm{Sb}$ & 0.35 & 0.18 & 0.3 & 0.15 & 0.31 & 0.45 \\
\hline
\end{tabular}

$\begin{array}{lllllllll}\text { Md } & 0.21 & 0.02 & 0.25 & 0.02 & 0.42 & 0.42 & 0.53\end{array}$

\begin{tabular}{l|l|l|l|l|l|l|l|l|} 
Bq & 0.25 & 0.09 & 0.2 & 0.09 & 0.18 & 0.24 & 0.44 & 0.3 \\
\hline
\end{tabular}

\begin{tabular}{lll|l|l|l|l|l|l|l|l|l} 
Mi & 0.17 & 0.31 & 0.39 & 0.44 & 0.27 & 0.31 & 0.35 & 0.44 & 0.26
\end{tabular}

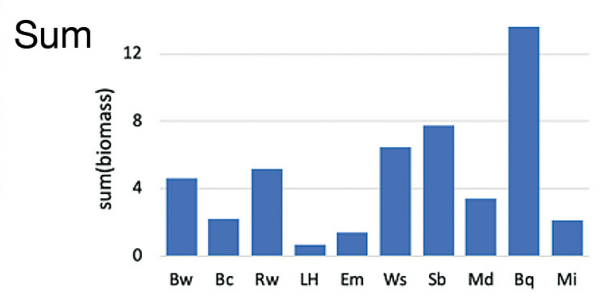

Fig. 10. Assemblage structure across the banks, which are ordered southwest (red) to northeast (blue), for (a) crustaceans, (b) echinoderms and (c) mollusks/Cirripedia. In each panel: average biomass ( $\mathrm{g} \mathrm{tow}^{-1}$ ) of species (left); Bray-Curtis similarity index (BCSI) matrix showing biomass-weighted BCSI for each bank pair (top right); and sum of all species' biomass ( $\mathrm{g}$ tow ${ }^{-1}$ ) 
Middle; average BCSI $=0.73$ ). Western Bank was distinct (though more similar to the SW banks [mean $\mathrm{BCSI}=0.48]$ than the NE [mean BCSI $=0.18]$ ), potentially indicating a transition zone related to increasing temperatures NE-SW (Figs. 5c \& 10a). Brown's Bank was also different due to the high biomass of American lobster (Fig. 10a); this bank has been closed to lobster fishing since 1979 to protect brood stock (DFO 2018). The average similarity between SW and NE bank crustacean assemblages was low (0.15), demonstrating a shift in the along-shelf structure.

The overall NE-SW gradients in assemblage structure and total biomass (Fig. 10a-c) were largely driven by gradients in the biomass of the most common species for all 3 groups but most strikingly for crustaceans and echinoderms (Supplement 3). We found that 4 of the 29 crustacean species (Homarus americanus, northern pink shrimp Pandalus borealis, P. montagui and C. opilio), 4 of 27 echinoderm species (Cucumaria frondosa, green sea urchin Strongylocentrotus droebachiensis, polar six-rayed star Leptasterias polaris and common sea star Asterias rubens) and 9 of 26 mollusk/Cirripedia species (sea scallop Placopecten magellanicus, barnacles, Iceland scallop Chlamys islandica, common mussel Mytilus edulis, New England neptune Neptunea lyrata, waved whelk Buccinum undatum, northern moonsnails [genus Euspira], dire whelk Lirabuccinum dirum and northern horse mussel Modiolus modiolus) accounted for $90 \%$ of the total biomass of their respective grouping (Supplement 3).

Compared to crustaceans, average similarities between the SW and NE clusters of echinoderm bank assemblages were low (0.32 and 0.36), as was Western Bank's similarity to the SW cluster (mean BCSI = 0.12 for echinoderms, compared to 0.48 for crustaceans). However, similarity of the Western Bank echinoderm assemblage to the NE cluster was slightly higher (mean BCSI $=0.33$; Fig. 10b) compared to a mean BCSI $=0.18$ for crustaceans. Six echinoderm species declined in biomass NE-SW. These included cold-water species $C$. frondosa, $S$. droebachiensis and L. polaris (Fig. 10b), which accounted for the largest proportion of the total echinoderm biomass across the banks (Supplement 3).

For mollusks/Cirripedia, average similarities within SW and NE banks were 0.35 and 0.39 , while Brown's Bank was distinct and Western Bank was more similar to Brown's (BCSI $=0.62$ ) than either the NE (mean $\mathrm{BCSI}=0.35$ ) or the SW banks (mean BCSI $=0.3$; Fig. 10b). The average similarity between NE and SW banks was low (0.26). Five of the 9 common mollusk/Cirripedia species exhibited NE-SW declines in average biomass, including $M$. edulis, N. lyrata, $L$. dirum, B. undatum and C. islandica (Fig. 10c).

\subsection{Environmental predictors of biomass-weighted assemblage structure}

The relationship between assemblage structure for the 3 species groups (Fig. 10a-c) and the habitat properties (Fig. 5) of the 10 banks was investigated using canonical correspondence analysis (CCA). Similar to earlier results (Fig. 10), bank assemblages partitioned into NE and SW groups along the dominant CCA axis, but only for crustaceans and mollusks/ Cirripedia (Fig. 11).

\subsubsection{Crustacean CCA}

Four NE and 4 SW banks (plus Western Bank) formed 2 groups, distinct by the sign of their relationships with the first and only significant axis of the CCA model for crustacean assemblages (Fig. 11a). The model was almost fully constrained by bank centroid distance along-shelf $(\mathrm{r}=-0.99, \mathrm{p}<0.001)$, which accounted for $68 \%$ of the interbank variation in relative species biomasses for crustaceans. The Roseway Bank assemblage was a significant outlier, at CCA1 = -0.91 and CCA2 $=-6.58$, which appears to be due to its relatively high mean peak chlorophyll concentration and proximity to the coast compared to the other banks (Fig. 5b).

\subsubsection{Echinoderm CCA}

The banks did not partition into NE and SW groupings of echinoderm assemblages (Fig. 11b). Rather, Baccaro (SW), LaHave (SW), Western (NE) and Sable (NE) Banks were distinguished from Brown's (SW), Roseway (SW), Middle (NE) and Banquereau (NE) Banks by their negative amplitudes for CCA1, while Sable and Roseway Banks were distinguished from the others by their negative amplitudes for CCA2 (Fig. 11b); Misaine and Emerald Banks were distinct outliers. The constrained CCA model accounted for $49 \%$ of the interbank variation in species biomasses (CCA1 $=26 \%$, CCA2 $=23 \%$ ). CCA1 was largely constrained by the composite retention index $(\mathrm{r}=-0.94)$, and depth $\mathrm{SD}(\mathrm{r}=$ $-0.70)$. CCA2 was constrained by the TS composite index $(\mathrm{r}=-0.59)$. Overall, retention accounted for $23 \%(\mathrm{p}<0.01)$, depth SD for $15 \%(\mathrm{p}<0.01)$ and TS 
a) Crustaceans

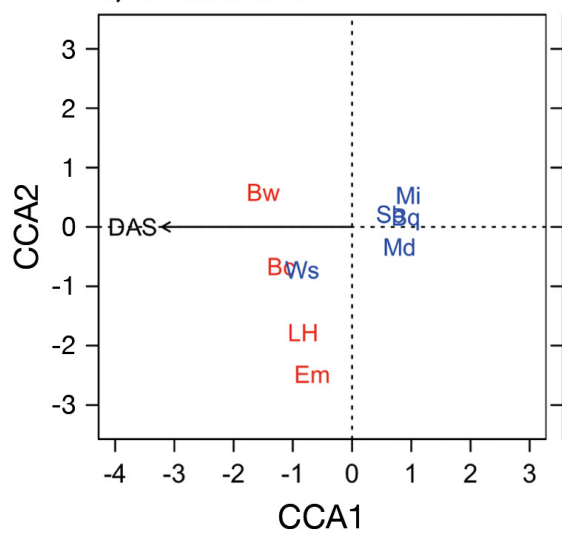

b) Echinoderms

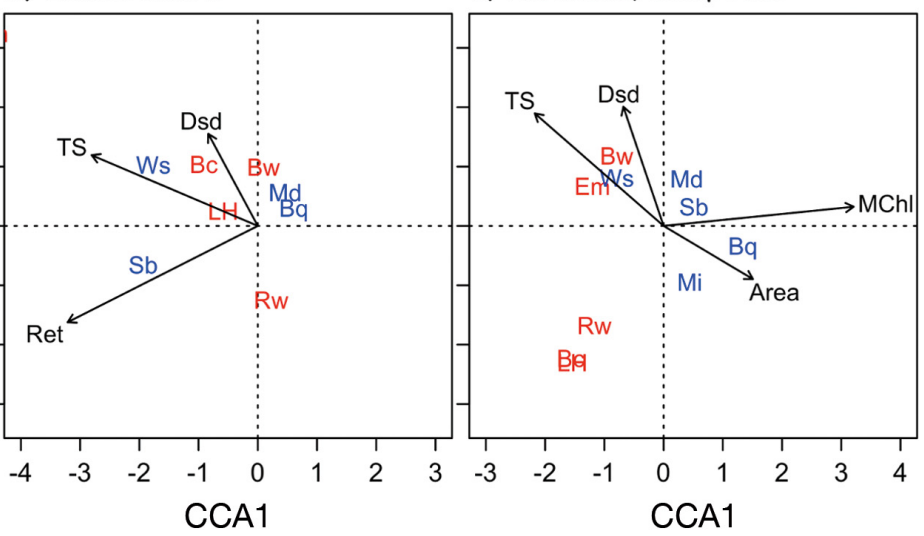

Fig. 11. Results of the sequential CCA model selection process for each group: (a) crustaceans, (b) echinoderms and (c) mollusks/Cirripedia. The 2 axes (CCA1 and CCA2) are constrained by the most important environmental filters for the group of interest and are shown as vectors. The environmental filters are: bank centroid distance along shelf (DAS), temperature/salinity composite (TS), depth standard deviation (Dsd), retention time (Ret), annual mean chlorophyll a concentration (MChl) and bank area (Area). Lengths of vectors are proportional to the contribution of the habitat property to the overall explanatory power of the CCA model. Abbreviations of bank names as in Fig. 1; NE banks are in blue, SW banks in red. Note that there are significant outliers, but to allow for expanded axes, these are not shown: (a) Roseway Bank at -0.91/-6.58, and (b) Emerald Bank at $-4.51 / 3.25$ and Misaine Bank at 0.92/-3.72

for $18 \%(p<0.05)$ of the interbank variation in species biomasses (Fig. 11b).

\subsubsection{Mollusk/Cirripedia CCA}

For the mollusks/Cirripedia, the analysis showed a counter-clockwise progression from the NE to the SW banks, with the lone exception of Brown's Bank, which was more like Western and Emerald Banks than its nearest neighbors (Fig. 11c). The constrained CCA model accounted for $82 \%$ of the interbank variation in species biomasses; the first 3 axes accounted for $80 \%(\mathrm{CCA} 1=35 \%, \mathrm{CCA} 2=28 \%, \mathrm{CCA} 3=17 \%)$. The first axis was constrained by annual mean chl a concentration $(\mathrm{r}=0.94)$ and TS composite $(\mathrm{r}=-0.54)$. The second axis was constrained by TS composite $(\mathrm{r}=0.66)$, and depth $\mathrm{SD}(\mathrm{r}=0.64)$. The third axis was constrained by depth SD $(r=-0.71)$ and bank area $(\mathrm{r}=-0.51)$. Overall, annual mean chl a concentration accounted for $32 \%(p<0.01)$, depth SD for $22 \%(p<$ $0.01)$, TS for $18 \%(\mathrm{p}<0.01)$ and bank area for $10 \%$ $(p<0.01)$ of the interbank variation in species biomasses (Fig. 11c).

\section{DISCUSSION AND CONCLUSIONS}

The offshore banks of the SS host 'island-like' assemblages within each of the 3 macroinvertebrate species groups of interest. Bank echinoderm and
mollusk/Cirripedia assemblages, in particular, were substantially more productive (higher biomass) compared to surrounding deeper regions (Fig. 6). These results agree with a broad literature base identifying the banks as ecological hotspots at multiple trophic levels (Rowell \& Chaisson 1983, Tremblay \& Roff 1983, Shackell \& Frank 2000, 2003, Rincón \& Kenchington 2016). Our initial hypothesis that SAR slopes for the species groups would be proportional to their relative adult motility and larval dispersal capacity was confirmed. Only the mollusk/Cirripedia assemblages of the SS banks, generally characterized by species with sessile adult life stages and short larval durations (Fig. 3), exhibited a steep and significant SAR slope (Fig. 8c). The taxon/group with the most motile adults and highest dispersal capacity, the crustaceans, had a SAR slope not significantly different from 0. Echinoderms which, given the data available, have an adult motility and larval dispersal capacity in between the other 2 species groupings, had a marginally significant SAR slope, slightly greater than that of crustaceans.

The SAR slope for mollusks/Cirripedia was 1.6 times greater than the highest slope (0.40) reported by Hachich et al. (2015) for gastropods in the coastal waters of islands spanning 60 degrees of latitude in the Atlantic Ocean. The banks of the SS are confined to a much smaller area, spanning only 3 degrees of latitude and 9 degrees of longitude. In our region, the high collinearity between bank area and other bank habitat properties (Fig. 5c), which could act as filters 
to species' colonization of the smaller SW banks from the upstream NE banks, may have strengthened the resulting SAR. Another potential explanation could be that analyses at larger spatial scales are subject to larger-scale patterns such as latitudinal diversity gradients (Roy et al. 1998, Willig et al. 2003, Tolimieri 2007, Fisher et al. 2008), which can obscure univariate relationships such as SARs (Whittaker 2000).

Further analysis indicated that habitat heterogeneity (collinear with area, $r=0.68$ ) was an equally important predictor of mollusk/Cirripedia alpha diversity (Fig. 9c). This was consistent with the TIB (MacArthur \& Wilson 1967), which attributed SARs, at least partially, to the fact that larger areas often provide a greater variety of habitats/niches. Mollusks/ Cirripedia was the only group characterized by individual species with depth distributions that varied widely from one another (Supplement 5), indicating that larger banks, especially those with a greater variety of depths (and therefore a greater variety of sediment types, i.e. niches; Kostylev \& Hannah 2007), support a greater variety of mollusk/Cirripedia species. Bank area and habitat heterogeneity accounted for an almost equal proportion of among-bank variance in alpha diversity for echinoderms (Figs. 8b \& 9b). However, both models were only marginally statistically significant, implying that we may have yet to identify the most important environmental processes driving interbank variation of echinoderm alpha diversity on the SS.

Crustaceans on the SS offshore banks exhibited a SAR slope (0.06) that was not significantly different from 0 and was significantly lower than crustacean SAR slope values compiled by Drakare et al. (2006; 0.24-0.36). We attribute this to the high interconnectivity among crustacean assemblages resulting from the combination of a strong NE-SW current (transiting shelf in 60-90 d), long larval durations (mean $91 \mathrm{~d}$ ) and highly motile adults (Pezzack \& Duggan 1986, Biron et al. 2008). Consistent with this attribution, the TS composite index (collinear with distance along shelf: $r=0.63$ ) was a significant predictor of crustacean alpha diversity (Fig. 9a). This result suggested that, while the banks in the NE were generally larger than those in the SW, the NE-SW decline in crustacean alpha diversity followed the gradient in temperatures and salinities on the banks, with the coolest and least saline banks being home to the greatest number of crustacean species.

We hypothesized that the relative insularity of the species groups would also be apparent in the structuring of their assemblages and the relative importance of physical (area and habitat heterogeneity) vs. oceanographic habitat properties as drivers of assemblage structure. Our results provided partial support for this hypothesis. Both physical and oceanographic habitat properties were important drivers of assemblage structure for mollusks/Cirripedia and echinoderms. Oceanographic properties accounted for slightly more variation in mollusk/Cirripedia assemblage structure than physical variables; the reverse was true for echinoderms. However, physical habitat characteristics were more important to the structuring of these less motile/dispersive groups relative to the more motile/dispersive crustaceans. The crustacean assemblages were structured largely by oceanographic habitat properties (Fig. 11a).

Both crustaceans and mollusks/Cirripedia exhibited a partitioning of the bank assemblages into 2 distinct complexes, one in the NE and one in the SW, separated by a transition zone at Western and Emerald Banks (Figs. 10a-c \& 11; similar to the partitioning of habitat properties as in Fig. 5c). However, the variation in mollusk/Cirripedia assemblage structure along the shelf was driven by the loss of $13 / 26$ species from the NE to the SW banks, the largest loss for any of the groups (Figs. 10c \& 12), while the variation in crustacean assemblage structure resulted largely from an average NE-SW decline in the biomass of many common crustacean species (Fig. 10a). In fact, when only presence/absence of species were considered, the NE and SW complexes of crustaceans were quite similar (average BCSI =0.6; Supplement 6), while the complexes remained different for mollusks/ Cirripedia (average BCSI $=0.39$; Supplement 6). The importance of distance along shelf as a predictor of crustacean assemblage structure (Fig. 11a) indicated that while most crustacean species were observed shelf-wide, the along-shelf decline in species' biomasses likely resulted from NE-SW shifts in temperature and other collinear habitat properties (Fig. 12). These findings agree with many species-specific studies, indicating that most SS larvae are transported NE to SW (Roff et al. 1986, Suthers \& Frank 1991, Frank 1992, Tremblay 1997, Reiss et al. 2000) and that temperature plays an important role in determining species distributions and therefore the species compositions of geographically defined assemblages (Pörtner 2002, Pinsky et al. 2013, Pörtner \& Gutt 2016).

Collinear variables, habitat heterogeneity and retention (a mechanism of isolation) played significant roles (together accounting for $38 \%$ of variance in assemblage structure, compared to $18 \%$ accounted for by TS) in structuring/filtering echinoderm assemblages (Fig. 11b). Greater insularity of assemblages 


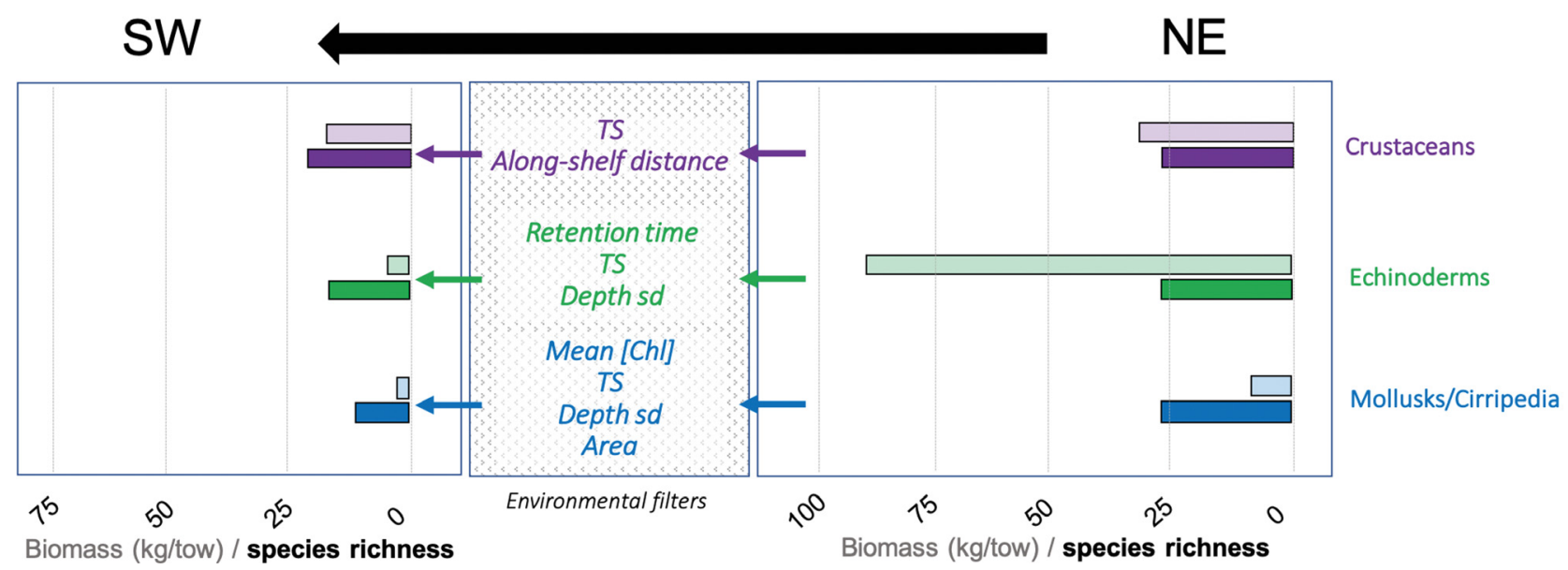

Fig. 12. Summary of results indicating NE-SW flow (arrows) and filtering (via variables in center panel, which emerged as important predictors of alpha diversity and assemblage structure through our analyses) of crustacean (purple), echinoderm (green) and mollusk/Cirripedia (blue) bank assemblage richness (darker bars) and biomass (lighter shaded bars). The NE banks and SW banks are grouped, as our results indicate these bank complexes may represent unique metacommunities connected via a 'source-sink' transport of species, filtered by the habitat properties that also differ between these 2 halves of the shelf (refer to Fig. 5)

of echinoderms relative to crustaceans may be further supported by the fact that 7 echinoderm species, compared to only 4 crustacean species, were observed on only 1 or 2 banks (Fig. 10b). This agrees with findings that the patchy distribution of $\mathrm{Cucu}$ maria frondosa on the SS was related to physical retention patterns, largely on the banks, combined with the low mobility of adults (Shackell et al. 2013). Although some common echinoderm species exhibited NE-to-SW declines in biomass (e.g. C. frondosa, Strongylocentrotus droebachiensis, Asterias rubens and Leptasterias polaris; Fig. 10b), the echinoderm bank assemblages did not partition into NE and SW groups in the CCA as they did for the crustaceans and mollusks/Cirripedia (Fig. 11). These results imply that habitat properties not collinear with distance along shelf, e.g. retention (Fig. 11b), are more important structuring forces within this group. However, the average similarity of NE and SW banks given only the presence/absence of species was much higher (0.7) than for mollusks/Cirripedia (0.39; Supplement 6), implying that, while the echinoderm assemblages consist of species with patchier distributions and are not as well-defined by a NE-SW gradient compared to the crustaceans, these assemblages are likely more interconnected than assemblages of mollusks/Cirripedia.

Unlike the highly connected crustacean and echinoderm assemblages, many (50\%) mollusk/Cirripedia species were unsuccessful in colonizing the SW banks, despite strong oceanographic flows (short timescales of connectivity: Supplement 1) and the poten- tial for intergenerational along-shelf transport. We attribute this to the combined effect of low adult mobility/short larval durations and environmental filtering (Cadotte \& Tucker 2017). The results of our CCA (Fig. 11c) suggest that likely filters include, in order of their contribution to the CCA model, resource availability (e.g. mean chl a concentration [32\%] and depth SD [22\%]), and/or species-specific temperature tolerance (e.g. TS [18\%]), preventing successful colonization of warmer banks downstream (also see Supplement 7; summary in Fig. 12). A further case for the importance of temperature as an environmental filter is made by the fact that at least 4 of the 13 mollusk/Cirripedia species that were observed only on the NE banks favor cold water: arctic surf clam Mactromeris polynyma, Greenland cockle Serripes groenlandicus, Greenland margarite Margarites groenlandica and Iceland moonsnail Amauropsis islandica (Fig. 10c).

A characteristic feature of the SS ecosystem is the collinearity of bank area, habitat heterogeneity, TS properties and chlorophyll concentration with alongshelf distance. In the case of sessile, low-dispersal mollusks/Cirripedia, this collinearity may have led to heightened insularity of bank assemblages (Fig. 8c) compared to other regions due to the substantial loss of species along the NE-SW trajectory (Fig. 10c). In the case of crustaceans, this collinearity may have resulted in the distinction of NE vs. SW complexes according to the relative biomass of species. As our analyses were correlative in nature, the relative contribution of these collinear variables to the structur- 
ing of these assemblages is difficult to decipher. However, these habitat properties were chosen a priori based on their relevance to macroinvertebrate ecology, resulting in low residual variability overall in the modeled alpha diversity $(39-54 \%$ variance accounted for) and biomass-weighted assemblage structure (66-82\% variance accounted for). Consequently, our models could be used to predict changes in macroinvertebrate assemblage structure for all 3 of our taxa/groups of interest on the SS under a shifting climate regime. Further, these models could be tested in other temperate regions where data on habitat heterogeneity, TS properties, chlorophyll and retention are available, but less inter-dependent, in order to gain insight into their relative importance.

Similar to the bimodal distribution of bank habitat properties between the NE and SW halves of the shelf (Fig. 5c), the distinction between NE and SW bank assemblages was most pronounced mid-shelf, at Emerald Bank. All 3 species groups exhibited decreases in biomass and alpha diversity between Western and Emerald Banks $\left(58,97\right.$ and $78 \%$ biomass [g tow ${ }^{-1}$ ], and 4/14, 8/17 and 11/13 species for crustaceans, echinoderms and mollusks/Cirripedia respectively; Fig. 10) despite the proximity of these banks to one another ( 10 $\mathrm{km}$ between closest boundaries). While Emerald Bank is smaller than the banks to the NE, it is not the smallest on the shelf, and is larger than the more speciose Baccaro and Roseway Banks to the SW. Moreover, the oceanographic properties of Western and Emerald Banks are quite similar; the root mean square difference is only $0.34 \mathrm{SD}$ (for the combination of normalized retention, TS, annual range of bottom temperature, mean and peak chlorophyll). However, there was a significant difference in depth SD between Emerald and Western Banks (depth SD is 1.2 SD lower on Emerald Bank; Fig. 5a). This may have contributed to the loss of species observed between these banks. Another possibility is that the oceanography of the shelf is more complicated than indicated by our generalization of the NESW flow. In fact, the Scotian Gulf, between Emerald and LaHave Banks, is a major conduit of intrusions of warm slope waters and outflow of shelf waters to the continental slope (Brickman \& Drozdowski 2012). This could result in the loss of propagules towards the coast or off-shelf during their transport between banks. Further, both Emerald and Western Banks have been noted as areas of high retention relative to the rest of the shelf (Cong et al. 1994) which may maintain discrete spawning aggregations of groundfish such as haddock (DFO 1996, Frank et al. 2000). In our assessment of particle trajectories using Web-
Drogue (Hannah et al. 2001), particles from Emerald Bank were largely retained on Emerald Bank, while particles from Western Bank were either retained or transported to the NE and towards the coast rather than along-shelf. In summary, our results indicate that the average directional flow of the NSC and its collinear habitat variables did result in along-shelf gradients in bank assemblage structure (particularly for crustaceans and mollusks/Cirripedia), but that the more complex oceanography of the system may have created a stronger transition point at Emerald Bank than would be anticipated if the average flow were considered alone. This result is consistent with recent evidence of a dramatic shift mid-shelf (around Emerald and Western banks) in the genetic structure of multiple species coherent with along-shelf temperature gradients (Stanley et al. 2018).

Further to this point, the along-shelf gradients in temperature and the relative strength of the alongshelf flow of cold NSC vs. influx of warm slope waters has not been consistent over time and has influenced along-shelf gradients in macroinvertebrate biomass in the past. Such variation has been particularly significant for high-dispersal crustacean species. For example, Pandalus borealis, a high-valued commercially exploited species, is near the limit of its southern range in the western SS/Gulf of Maine (GOM). It has periodically flourished in these regions, particularly during the late 1960s and mid-1990s when record high landings occurred. These events were preceded by periods of low bottom water temperatures and weakened along-shelf temperature gradients (Petrie \& Drinkwater 1993, Hebert et al. 2016). Richards et al. (2012) suggested that shrimp recruitment is governed by water temperature operating directly on larval growth/mortality or indirectly through timing of hatching in relation to phytoplankton blooms. The possibility of connectivity of the GOM stock with upstream sources through larval dispersal has not been considered as a contributor to the periodic bouts of enhanced GOM shrimp productivity, but our study suggests this mechanism should be given serious consideration, not just for shrimp but possibly for other crustacean species.

The evident contrast between NE and SW bank assemblages, correlations between assemblage structure and along-shelf gradients in habitat properties, and the fact that the relative insularity of assemblages (reflected in SAR slopes) of the 3 macroinvertebrate species groups investigated was inversely proportional to their relative adult motility and larval dispersal capacity implies that the banks of the SS represent 2 distinct meta-communities (sensu Lei- 
bold et al. 2004) connected via the NSC. The degree to which these 2 meta-communities are connected relies on the strength of the NSC, the motility and larval dispersal capacity of the species group, speciesspecific habitat preferences and the degree to which the temperature gradient and influx/outflow of warm slope water creates a barrier at Emerald Bank. Indeed, banks, due to their unique habitat, function as islands especially when dispersal is low (e.g. strong SAR for mollusks/Cirripedia), but are also naturally connected via ocean currents, larval dispersal and active movements of more motile adults.

The large heterogeneous NE banks appear to represent a recruitment source for the small bank-dominated SW, and may be especially so in years when the temperature gradient is weakened, as in the $P$. borealis example provided above. In light of our findings, it is recommended that greater attention be paid to the functional significance of the large, speciose and productive 'source' NE banks when considering the establishment of protective zones and the management of commercially important species. A number of common crustacean, echinoderm and mollusk/Cirripedia species exhibiting NE-SW declines in biomass are commercially harvested or under consideration for future exploitation (e.g. emerging or developing fisheries for Cancer irroratus, C. borealis, Cucumaria frondosa, S. droebachiensis, Spisula solidissima, A. islandica, M. polynyma, Littorinidae), despite limited ecological knowledge (Anderson et al. 2008). Our results may alert managers to take a cautious approach in setting harvest limits for the NE banks complex in order to protect their shelf-wide importance to downstream banks and the GOM. Perry et al. (1999) suggested marine protected areas or temporary fisheries closures be implemented to protect source populations, such that surrounding/sink populations may be sustainably harvested. This is particularly important where knowledge of the biology of targeted (and bycatch) species is limited and potential environmental variability may threaten the stability of populations as well. Protecting upstream, heterogeneous bank assemblages may buffer against the effects of overharvesting and climate change on the diversity of macroinvertebrates and the sustainability of current and developing invertebrate fisheries of the SS.

Data availability. Data are available in Supplement 8 at www.int-res.com/articles/suppl/m641p025_supp8.xlsx: (1) Average biomass per tow of species on each bank within each group, and (2) Average bank habitat characteristics, raw species counts ('sr'), and Jackknife1 alpha diversity estimates ('jack') for each group, for each bank.
Acknowledgements. We thank Dr. Nigel Yoccoz and Dr. Edda Johannesen for their advice and support regarding the CCA approach to community structure analysis; Cathy Porter, Carla Caverhill and Shelley Bond for chlorophyll data extraction, organization, and support; Chantelle Layton for advice concerning the estimation of peak chlorophyll values; Adam Drozdowski and Dr. Charles Hannah for support regarding the use of the WebDrogue particle-tracking model; and Brian Bower for help accessing bathymetric data for mapping off-campus. We also thank Mike McMahon and Mark Fowler, for crucial support regarding the use of Fisheries and Oceans Canada summer research vessel survey data. This work was funded by the Natural Sciences and Engineering Research Council of Canada (NSERC) Discovery Grants Program. We extend our sincerest appreciation for the insightful, constructive and thought-provoking comments on our manuscript provided by the anonymous reviewers.

\section{LITERATURE CITED}

Anderson SC, Lotze HK, Shackell NL (2008) Most common/abundant species within each taxon are generally commercially harvested and these species drive assemblage structure. Can J Fish Aquat Sci 65:2553-2571

Ashford OS, Kenny AJ, Barrio Froján CR, Horton T, Rogers $A D$ (2019) Investigating the environmental drivers of deep-seafloor biodiversity: A case study of peracarid crustacean assemblages in the Northwest Atlantic Ocean. Ecol Evol 9(24): 14167-14204

Baums IB, Paris CB, Cherubin LM (2006) A bio-oceanographic filter to larval dispersal in a reef-building coral. Limnol Oceanogr 51:1969-1981

* Bay LK, Buechler K, Gagliano M, Caley MJ (2006) Intraspecific variation in the pelagic larval duration of tropical reef fishes. J Fish Biol 68:1206-1214

* Biron M, Ferron C, Moriyasu M (2008) Movement of adult male snow crab, Chionoecetes opilio, in the southern Gulf of St. Lawrence and eastern Nova Scotia, Canada. Fish Res 91:260-270

Breeze H, Fenton DG, Rutherford RJ, Silva MA (2002) The Scotian Shelf: an ecological overview for ocean planning. Can Tech Rep Fish Aquat Sci 2393:1-259

Brickman D, Drozdowski A (2012) Atlas of model currents and variability in Maritime Canadian waters. Can Tech Rep Hydrogr Ocean Sci 277:1-64

Burnham KP, Anderson DR (2002) Model selection and multimodel inference-a practical information theoretic approach, $2^{\text {nd }}$ edn. Springer, New York, NY

Caddy JF (1968) Underwater observations on scallop (Placopecten magellanicus) behaviour and drag efficiency. J Fish Res Board Can 25:2123-2141

Cadotte MW, Tucker CM (2017) Should environmental filtering be abandoned? Trends Ecol Evol 32:429-437

* Chapman DC, Beardsley RC (1989) On the origin of shelf water in the Middle Atlantic Bight. J Phys Oceanogr 19: 384-391

Cong L, Sheng J, Thompson KR (1996) A retrospective study of particle retention on the outer banks of the Scotian Shelf, 1956-1993. Can Tech Rep Hydrogr Oceanogr Sci 170:1-132

Dawson MN (2016) Island and island-like marine environments. Glob Ecol Biogeogr 25:831-846

* De Bie T, De Meester L, Brendonck L, Martens K and others (2012) Body size and dispersal mode as key traits deter- 
mining metacommunity structure of aquatic organisms. Ecol Lett 15:740-747

DFO (Fisheries and Oceans Canada) (1996) Eastern Scotian Shelf haddock. DFO Atlantic Fisheries Stock Status Report 96/68E. https://waves-vagues.dfo-mpo.gc.ca/Library/ 40637499.pdf

DFO (2017) 2016 Maritimes research vessel survey trends on the Scotian Shelf and Bay of Fundy. DFO Can Sci Advis Sec Sci Rep 2017/004. https://waves-vagues.dfompo.gc.ca/Library/4062092x.pdf

DFO (2018) Assessment of lobster (Homarus americanus) in Lobster Fishing Area 41 (4X + 5Z) for 2016. DFO Can Sci Advis Sec Sci Advis Rep 2018/004. https://waves-vagues. dfo-mpo.gc.ca/Library/40711730.pdf

Dormann CF, Elith J, Bacher S, Buchmann C and others (2013) Collinearity: a review of methods to deal with it and a simulation study evaluating their performance. Ecography 36:27-46

Doubleday WG, Rivard D (1981) Bottom trawl surveys. Publ Spec Can Sci Halieut Aquat 47:385-394

Drakare S, Lennon JJ, Hillebrand H (2006) The imprint of the geographical, evolutionary and ecological context on species-area relationships. Ecol Lett 9:215-227

Edgar GJ, Banks S, Fariña JM, Calvopiña M, Martínez C (2004) Regional biogeography of shallow reef fish and macro-invertebrate communities in the Galapagos archipelago. J Biogeogr 31: 1107-1124

Fisher JAD, Frank KT (2002) Changes in finfish community structure associated with an offshore fishery closed area on the Scotian Shelf. Mar Ecol Prog Ser 240:249-265

Fisher JAD, Frank KT, Petrie B, Leggett WC, Shackell NL (2008) Temporal dynamics within a contemporary latitudinal diversity gradient. Ecol Lett 11:883-897

Fox J, Monette G (1992) Generalized collinearity diagnostics. J Am Stat Assoc 87:178-183

Frank KT (1992) Demographic consequences of age-specific dispersal in marine fish populations. Can J Fish Aquat Sci 49:2222-2231

Frank KT, Shackell NL (2001) Area-dependent patterns of finfish diversity in a large marine ecosystem. Can J Fish Aquat Sci 58:1703-1707

Frank KT, Shackell NL, Simon JE (2000) An evaluation of the Emerald/Western Bank juvenile haddock closed area. ICES J Mar Sci 57:1023-1034

Franzén M, Schweiger O, Betzholtz PE (2012) Species-area relationships are controlled by species traits. PLOS ONE $7: \mathrm{e} 37359$

Graham MH (2003) Confronting multicollinearity in ecological multiple regression. Ecology 84:2809-2815

* Grantham BA, Eckert GL, Shanks AL (2003) Dispersal potential of marine invertebrates in diverse habitats. Ecol Appl 13:108-116

Hachich NF, Bonsall MB, Arraut EM, Barneche DR, Lewinsohn TM, Floeter SR (2015) Island biogeography: patterns of marine shallow-water organisms in the Atlantic Ocean. J Biogeogr 42:1871-1882

Halliday RG, Pinhorn AT (1990) The delimitation of fishing areas in the Northwest Atlantic. J Northw Atl Fish Sci 10:1-51

* Hamel JF, Mercier A (1996) Early development, settlement, growth, and spatial distribution of the sea cucumber, Cucumaria frondosa (Echinodermata: Holothuroidea). Can J Fish Aquat Sci 53:253-271

Hamel JF, Sun J, Gianasi BL, Montgomery EM and others (2019) Active buoyancy adjustment increases dispersal potential in benthic marine animals. J Anim Ecol 88: 820-832

Hannah CG, Shore JA, Loder JW (2000) The retention-drift dichotomy on Browns Bank: a model study of interannual variability. Can J Fish Aquat Sci 57:2506-2518

Hannah CG, Shore JA, Loder JW, Naimie CE (2001) Seasonal circulation on the western and central Scotian Shelf. J Phys Oceanogr 31:591-615

Hebert D, Pettipas R, Brickman D, Dever M (2016) Meteorological, sea ice and physical oceanographic conditions on the Scotian Shelf and in the Gulf of Maine during 2015. DFO Sci Advis Sec Res Doc 2016/083. https://wavesvagues.dfo-mpo.gc.ca/Library/40575214.pdf

Itescu Y (2019) Are island-like systems biologically similar to islands? A review of the evidence. Ecography 42: 1298-1314

Johnson C, Devred E, Casault B, Head E, Spry J (2018) Optical, chemical and biological oceanographic conditions on the Scotian Shelf and in the Eastern Gulf of Maine in 2016. DFO Can Sci Advis Sec Res Doc 2018/017. www. dfo-mpo.gc.ca/csas-sccs/Publications/ResDocs-DocRech/ 2018/2018_017-eng.html

Koeller P, Fuentes-Yaco C, Platt T, Sathyendranath S and others (2009) Basin-scale coherence in phenology of shrimps and phytoplankton in the North Atlantic Ocean. Science 324(5928):791-793

Kostylev VE, Hannah CG (2007) Process-driven characterization and mapping of seabed habitats. Mapping the seafloor for habitat characterization. Spec Pap 47:171184. Geological Association of Canada, Dartmouth

Legendre P, Legendre L (2012) Numerical ecology, $3^{\text {rd }}$ English edn. Elsevier, Kidlington

KLeibold MA, Holyoak M, Mouquet N, Amarasekare P and others (2004) The metacommunity concept: a framework for multi-scale community ecology. Ecol Lett 7:601-613

K Loder JW, Ross CK, Smith PC (1988) A space- and time-scale characterization of circulation and mixing over submarine banks, with application to the northwestern Atlantic continental shelf. Can J Fish Aquat Sci 45:1860-1885

Loder JW, Petrie B, Gawarkiewicz G (1998) The coastal ocean off northeastern North America: a large-scale view. In: Robinson ER, Brink KH (eds) The sea, Vol 11. John Wiley and Sons, New York, NY, p 105-133

Loder JW, Shore JA, Hannah CG, Petrie BD (2001) Decadalscale hydrographic and circulation variability in the Scotia-Maine region SUM. Deep Sea Res II 48:3-35

MacArthur RH, Wilson EO (1967) The theory of island biogeography. Princeton University Press, Princeton, NJ

* Mahon R, Smith RW (1989) Demersal fish assemblages on the Scotian Shelf, Northwest Atlantic: spatial distribution and persistence. Can J Fish Aquat Sci 46(Suppl 1):134-152

Manuel JL, Dadswell MJ (1991) Swimming behavior of juvenile giant scallop, Placopecten magellanicus, in relation to size and temperature. Can J Zool 69:2250-2254

* Marshall DJ, Keough MJ (2003) Variation in the dispersal potential of non-feeding invertebrate larvae: the desperate larva hypothesis and larval size. Mar Ecol Prog Ser 255:145-153

Mazerolle MJ (2019) AICcmodavg: Model selection and multimodel inference based on (Q)AIC(c). R package version 2.1-1. https://cran.r-project.org/package= AICcmodavg

* McLaren IA, Avendaño P (1995) Prey field and diet of larval cod on Western Bank, Scotian Shelf. Can J Fish Aquat Sci 52:448-463 
Meyer KS (2017) Islands in a sea of mud: insights from terrestrial island theory for community assembly on insular marine substrata. Adv Mar Biol 76:1-40

* Meyer KS, Young CM, Sweetman AK, Taylor J, Soltwedel T, Bergmann M (2016) Rocky islands in a sea of mud: biotic and abiotic factors structuring deep-sea dropstone communities. Mar Ecol Prog Ser 556:45-57

Miller K, Williams A, Rowden AA, Knowles C, Dunshea G (2010) Conflicting estimates of connectivity among deepsea coral populations. Mar Ecol 31:144-157

Moritz C, Meynard CN, Dezictor V, Guizien K, Labrune C, Guarini JM, Mouquet N (2013) Disentangling the role of connectivity, environmental filtering, and spatial structure on metacommunity dynamics. Oikos 122: 1401-1410

Mouquet N, Miller TE, Daufresne T, Kneitel JM (2006) Consequences of varying regional heterogeneity in sourcesink metacommunities. Oikos 113:481-488

O'Boyle RN, Sinclair M, Conover RJ, Mann KH, Kohler AC (1984) Temporal and spatial distribution of ichthyoplankton communities of the Scotian Shelf in relation to biological, hydrological, and physiographic features. Rapp P-V Reun Cons Int Explor Mer 183:27-40

Oksanen J, Blanchet FG, Friendly M, Kindt R and others (2019) vegan: community ecology package. $R$ package version 2.5-2. https://CRAN.R-project.org/package=vegan

Palmer MW (1993) Putting things in even better order: the advantages of canonical correspondence analysis. Ecology 74:2215-2230

Palumbi SR (2003) Population genetics, demographic connectivity, and the design of marine reserves. Ecol Appl 13:146-158

Perry RI, Smith SJ (1994) Identifying habitat associations of marine fishes using survey data: an application to the northwest Atlantic. Can J Fish Aquat Sci 51:589-602

Perry RI, Walters CJ, Boutillier JA (1999) A framework for providing scientific advice for the management of new and developing invertebrate fisheries. Rev Fish Biol Fish 9:125-150

* Petrie B, Drinkwater K (1993) Temperature and salinity variability on the Scotian Shelf and in the Gulf of Maine 1945-1990. J Geophys Res 98:20079-20089

Pezzack DS, Duggan DR (1986) Evidence of migration and homing of lobsters (Homarus americanus) on the Scotian Shelf. Can J Fish Aquat Sci 43:2206-2211

Pinsky ML, Worm B, Fogarty MJ, Sarmiento JL, Levin SA (2013) Marine taxa track local climate velocities. Science 341:1239-1242

Pörtner HO (2002) Climate variations and the physiological basis of temperature dependent biogeography: systemic to molecular hierarchy of thermal tolerance in animals. Comp Biochem Physiol A Mol Integr Physiol 132: 739-761

Pörtner HO, Gutt J (2016) Impacts of climate variability and change on (marine) animals: physiological underpinnings and evolutionary consequences. Integr Comp Biol 56:31-44

Puritz JB, Keever CC, Addison JA, Barbosa SS and others (2017) Life-history predicts past and present population connectivity in two sympatric sea stars. Ecol Evol 7: 3916-3930

Reiss CS, Panteleev G, Taggart CT, Sheng J, DeYoung B (2000) Observations on larval fish transport and retention on the Scotian Shelf in relation to geostrophic circulation. Fish Oceanogr 9:195-213
Richards RA, Fogarty MJ, Mountain DG, Taylor MH (2012) Climate change and northern shrimp recruitment variability in the Gulf of Maine. Mar Ecol Prog Ser 464: 167-178

Rincón B, Kenchington EL (2016) Influence of benthic macrofauna as a spatial structuring agent for juvenile haddock (Melanogrammus aeglefinus) on the Eastern Scotian Shelf, Atlantic Canada. PLOS ONE 11:e0163374

Roddick DL, Lemon D (1992) Exploratory survey for small Arctic surfclams on the eastern Scotian Shelf. Canadian Industry Report of Fisheries and Aquatic Sciences 215, Halifax

Roff JC, Fanning LP, Stasko AB (1986) Distribution and association of larval crabs (Decapoda: Brachyura) on the Scotian Shelf. Can J Fish Aquat Sci 43:587-599

Rogers AD (1994) The biology of seamounts. Adv Mar Biol 30:305-350

Rowell TW, Chaisson DR (1983) Distribution and abundance of the ocean quahaug (Arctica islandica) and Stimpson's surf clam (Spisula polynyma) resource on the Scotian Shelf. Canadian Industry Report of Fisheries and Aquatic Sciences 142, Halifax

Koy K, Jablonski D, Valentine JW, Rosenberg G (1998) Marine latitudinal diversity gradients: tests of causal hypotheses. Proc Natl Acad Sci USA 95:3699-3702

* Shackell NL, Frank KT (2000) Larval fish diversity on the Scotian Shelf. Can J Fish Aquat Sci 57:1747-1760

* Shackell NL, Frank KT (2003) Marine fish diversity on the Scotian Shelf, Canada. Aquat Conserv 13:305-321

Shackell NL, Brickman DW, Frank KT (2013) Reserve site selection for data-poor invertebrate fisheries using patch scale and dispersal dynamics: a case study of sea cucumber (Cucumaria frondosa). Aquat Conserv 23:723-731

* Shank T (2010) Seamounts: deep-ocean laboratories of faunal connectivity, evolution, and endemism. Oceanography 23:108-122

* Shank TM, Halanych KM (2007) Toward a mechanistic understanding of larval dispersal: insights from genomic fingerprinting of the deep-sea hydrothermal vent tubeworm Riftia pachyptila. Mar Ecol 28:25-35

Shanks AL (2009) Pelagic larval duration and dispersal distance revisited. Biol Bull (Woods Hole) 216:373-385

Shurin JB, Winder M, Adrian R, Keller W and others (2010) Environmental stability and lake zooplankton diversitycontrasting effects of chemical and thermal variability. Ecol Lett 13:453-463

* Siegel DA, Kinlan BP, Gaylord B, Gaines SD (2003) Lagrangian descriptions of marine larval dispersion. Mar Ecol Prog Ser 260:83-96

* Smith EP, van Belle G (1984) Nonparametric estimation of species richness. Biometrics 40:119-129

* Stanley RRE, DiBacco C, Lowen B, Beiko RG and others (2018) A climate-associated multispecies cryptic cline in the northwest Atlantic. Sci Adv 4:eaaq0929

Stortini CH, Frank KT, Leggett WC, Shackell NL, Boyce DG (2018) Support for the trophic theory of island biogeography across submarine banks in a predator-depleted large marine ecosystem. Mar Ecol Prog Ser 607:155-169

Sutcliffe WH Jr, Loucks RH, Drinkwater KF (1976) Coastal circulation and physical oceanography of the Scotian Shelf and the Gulf of Maine. J Fish Res Board Can 33: 98-115

Suthers IM, Frank KT (1991) Comparative persistence of marine fish larvae from pelagic versus demersal eggs off southwestern Nova Scotia, Canada. Mar Biol 108:175-184 
Tolimieri N (2007) Patterns in species richness, species density, and evenness in groundfish assemblages on the continental slope of the US Pacific coast. Environ Biol Fishes 78:241-256

Tremblay MJ (1997) Snow crab (Chionoecetes opilio) distribution limits and abundance trends on the Scotian Shelf. J Northwest Atl Fish Sci 21:7-22

Tremblay MJ, Roff JC (1983) Community gradients in the Scotian Shelf zooplankton. Can J Fish Aquat Sci 40: 598-611

Tremblay MJ, Black GAP, Branton RM (2007) The distribution of common decapod crustaceans and other invertebrates recorded in annual ecosystem surveys of the Scotian Shelf 1999-2006. Can Tech Rep Fish Aquat Sci 2762:1-74

Triantis KA, Guilhaumon F, Whittaker RJ (2012) The island species-area relationship: biology and statistics. J Biogeogr 39:215-231

van Noordwijk CGET, Verberk WCEP, Turin H, Heijerman

Editorial responsibility: Pei-Yuan Qian,

Kowloon, Hong Kong SAR
T and others (2015) Species-area relationships are modulated by trophic rank, habitat affinity, and dispersal ability. Ecology 96:518-531

*Whittaker RJ (2000) Scale, succession and complexity in island biogeography: Are we asking the right questions? Glob Ecol Biogeogr 9:75-85

Williams CB (1964) Patterns in the balance of nature. Academic Press, London

*Willig MR, Kaufman DM, Stevens RD (2003) Latitudinal gradients of biodiversity: pattern, process, scale, and synthesis. Annu Rev Ecol Evol Syst 34:273-309

*Winter MA, Hamilton PV (1985) Factors influencing swimming in bay scallops, Argopecten irradians (Lamarck, 1819). J Exp Mar Biol Ecol 88:227-242

Young CM, He R, Emlet RB, Li YZ and others (2012) Dispersal of deep-sea larvae from the intra-American seas: simulations of trajectories using ocean models. Integr Comp Biol 52:483-496

Submitted: November 5, 2019; Accepted: March 19, 2020

Proofs received from author(s): April 30, 2020 